\title{
Composing wie wenn-the semantics of hypothetical comparison clauses in German
}

\author{
Sebastian Bücking ${ }^{1}$
}

Received: 7 November 2015 / Accepted: 22 February 2017 / Published online: 10 April 2017

(C) The Author(s) 2017. This article is published with open access at Springerlink.com

\begin{abstract}
This paper addresses the compositional semantics of hypothetical comparison clauses (= HCCs) in German. HCCs are introduced by either wie ('how') or als ('as'); for example, Ben fährt Rad, \{wie wenn er betrunken wäre / als wenn er betrunken wäre / als ob er betrunken wäre / als wäre er betrunken\} ('Ben is cycling as if he were drunk'). I argue for the following hypotheses: (i) Based on an explicit conditional antecedent, HCCs license the interpolation of hypothetical scenarios that give rise to an equivalence relation between entities provided by these scenarios and the given explicit matrix information. (ii) The equivalence relation may hold either between particularized properties (e.g., manners) of hypothetical events and the given matrix event (= V-HCCs), or between hypothetical topic situations and the matrix situation against which the given matrix clause as a whole is evaluated (=S-HCCs). The proposed semantic distinction is traced back to a structural contrast and, thus, is compositionally motivated: V-HCCs relate to the verbal head of the matrix clause, while $\mathrm{S}$-HCCs are non-integrated CP-adjuncts. (iii) Both wie and als lexically encode the relevant mediating equivalence relation; while HCCs with wie allow a regular compositional interpretation in terms of by and large ordinary free relative clauses, als projects rather idiosyncratic semantic (and syntactic) properties.
\end{abstract}

Keywords Adverbial clauses · Event semantics · Situation semantics · Conditionals · Comparison

\section{Introduction}

This paper is concerned with the semantics of hypothetical comparison clauses (= HCCs) in German. HCCs appear in four canonical forms: als ('as') may be com-

S. Bücking

sebastian.buecking@uni-tuebingen.de

1 Eberhard-Karls-Universität Tübingen, Wilhelmstr. 50, 72072 Tübingen, Germany 
bined with wenn ('if'), $o b$ ('whether'), or verb first, as in (1); wie ('how') only allows wenn, as in (2). ${ }^{1}$

(1) a. Ben fährt Rad als wenn er betrunken wäre.

Ben cycles as if he drunk were

'Ben is cycling as if he were drunk.'

b. Ben fährt Rad als $o b \quad$ er betrunken wäre.

Ben cycles as whether he drunk were

c. Ben fährt Rad als wäre er betrunken.

Ben cycles as were he drunk

(2) a. Ben fährt Rad wie wenn er betrunken wäre.

Ben cycles how if he drunk were

b. * Ben fährt Rad wie $o b \quad$ er betrunken wäre.

Ben cycles how whether he drunk were

c. * Ben fährt Rad wie wäre er betrunken.

Ben cycles how were he drunk

(see Bücking 2015: ex. (1), (2))

In recent decades, the syntactic properties of HCCs in their varying forms, their distribution, and their historical development have received much attention (see Kaufmann 1973; Oppenrieder 1991; Hahnemann 1999; Jäger 2010; Pauly 2013; Demske 2014; Bücking 2015). Although their interpretation is not fully ignored (see Kasper 1987 and Eggs 2006 for a corresponding focus), the semantic properties of HCCs have not been discussed in detail. Thus, explicit semantic representations, let alone attempts at deriving them from independently motivated structural components, are still missing. This paper aims at closing this gap and, thereby, providing a considerably refined look at HCCs' key grammatical and pragmatic traits.

A semantic analysis of HCCs faces the following challenges. For a start, one would like to find out how the conditional antecedent—which is transparent at least in the examples with wie wenn-and the introductory als or wie conspire to produce the peculiar interpretation HCCs have; note, in particular, that HCCs seem to lack a proper consequent. The HCCs in (1) and (2) suggest that Ben is cycling in wiggly lines; they receive a manner interpretation. A first approximation of this reading is given by the rough paraphrase in (3).

(3) Ben is cycling in a way that holds true of his cycling if he is drunk.

Hence, the analysis of such HCCs ties in with the more general question of what manner modifiers are and how they are compositionally derived. One complication arises from the observation that HCCs also allow what I will call a predicative reading, as, for instance, in (4). The afterthought introduced by nämlich ('namely') indicates that

\footnotetext{
${ }^{1}$ One may also use als wie wenn together; see Jäger (2010) and Bücking (2015) for a brief discussion. This is reminiscent of the simultaneous use of als and wie in non-hypothetical comparisons, which is usually considered nonstandard (see Eisenberg et al. 2005: $§ 503$ ). As pointed out by one reviewer, wie can also precede als-HCCs as wholes. For reasons of space, I cannot systematically discuss these additional options in more detail here.
} 
the property that is to be inferred from the HCC does not apply to the manner of the dressing, but to the resultant property of the agent's clothing. ${ }^{2}$

(4) Ben kleidet sich wie wenn er in die Oper ginge, nämlich elegant. Ben dresses how if he to the opera went namely elegant 'Ben is dressing as if he went to the opera, namely, elegant.'

A further desideratum results from the fact that HCCs may relate not only to the verbal projection ( $=\mathrm{V}-\mathrm{HCCs}$ ), but also to full sentences, as in (5).

(5) Er geht tatsächlich nach Hause - als ob er krank wäre. he goes in fact home as whether he ill were 'He is in fact going home-as if he were ill.' (see Kasper 1987: ex. (170))

Such sentential HCCs (= S-HCCs) do not receive a manner or predicative interpretation. Kasper (1987) considers them comments on facts. This characterization calls for an adequate specification; most importantly, it must be clarified to what extent both V-HCCs and S-HCCs share a common core, and which systematic factors may explain the distinctive effects on interpretation.

As will be shown in the upcoming discussion, HCCs introduced by wie are more regular than HCCs introduced by als. I will therefore focus on the composition of wie-HCCs here; a brief outlook on als-HCCs will be given at the end of the paper. In a nutshell, I will argue that the conditional antecedent within wie-HCCs licenses the interpolation of hypothetical scenarios; these, in turn, serve as the basis of a comparison that is mediated by the introductory wie: in V-HCCs, the given matrix event and hypothetical implicit events share equivalent event-internal particularized properties (such as manners or resultant properties); in S-HCCs, the proposed equivalence relation is argued to hold between the matrix topic situation and hypothetical ones. In order to flesh out the composition, I will bring together various independently motivated components - the perspective on modality and conditionals as proposed by Kratzer (1991a,b), an ontology that has events, particularized properties of events and situations at its disposal (see Piñón 2008; Schäfer 2013; Kratzer 2010), and a conception of equivalence in terms of equivalence relative to selected attributes (see Umbach and Gust 2014). The semantic contrast between V-HCCs and S-HCCs will be traced back to different syntactic landing sites as fed by different types of clausal linkage.

While the present paper focuses on specific structures in German, the results have more general implications: for one, the proposal for HCCs might be inspiring for detailed analyses of similar constructions in other languages (obviously, as if in English also introduces hypothetical comparisons). Furthermore, while different types of clausal linkage figure prominently in syntactic research on adverbial clauses, their compositional effects are rarely spelled out in substantial depth. This is particularly true for adverbial clauses that relate to the (lower) verbal domain. Finally, in view of their structural variants, HCCs in German are a challenging test case for the question

\footnotetext{
${ }^{2}$ The label 'predicative' is only meant to capture the intuition that the relevant property relates to an event participant. It does not say that manner and predicative HCCs differ syntactically; in fact, I will derive both interpretations by integrating the corresponding HCCs as adverbial modifiers in the immediate vicinity of the superordinate verbal head.
} 
of how to properly deal with the effects of both 'constructional' idiosyncrasies and regular composition at the syntax-semantics interface. The stepwise composition of HCCs with wie will reveal regularities that a 'constructional' view on such complex adverbials would miss. HCCs with als, by contrast, will be argued to comply with compositional principles only at the cost of hard-coding their syntactic and semantic idiosyncrasies within the lexicon.

The paper is structured as follows: in Sects. 2 and 3, I will overview the core characteristics of V-HCCs and S-HCCs introduced by wie wenn ('how if'). In Sects. 4 and 5, the respective composition of V-HCCs and S-HCCs will be spelled out in detail. In Sect. 6, the less regular form types with als ('as') will be briefly discussed. Sect. 7 offers a conclusion.

\section{V-HCCs with wie}

Most scholars agree that V-HCCs typically receive a manner interpretation. ${ }^{3}$ Following Kasper (1987), the conditional antecedent serves to select possible worlds. So the example in (6) (repeating (2a) from above) can be said to be true iff the manner of Ben's actual cycling "corresponds" (Kasper 1987: 136) to the manner of cycling in the selected possible worlds.

\footnotetext{
${ }^{3}$ A very different approach is defended by Eggs (2006). She argues (based mainly on als-HCCs) that VHCCs such as (i) "allow the speaker to express - by way of a hypothesis - an explanation for the state of affairs given in the main clause" (Eggs 2006: 176, my translation). In turn, they license abductive reasoning as exemplified in (ii).

(i) Anna geht, als ob sie einen Stein im Schuh hätte. Anna walks as whether she a stone in the shoe had 'Anna walks as if she had a stone in her shoe.'

(ii) a. Generic premise: If someone has a stone in his shoe $(p)$, then he walks strangely and hobbles $(q)$.

b. Specific premise: Anna is walking strangely and hobbling $(q)$.

c. Conclusion: She has (presumably) a stone in her shoe $(p)$. $\ldots$ as if she had a stone in her shoe $(p)$

(see Eggs 2006: ch. 3.3, ex. (47) and 176)
}

For both descriptive and theoretical reasons, I consider this view clearly inadequate. For instance, questions that call for making a presumed explanation explicit are at odds with V-HCCs. Hence, 'What's up with Anna?' can be answered by (iiia), but not by (iiib).

(iii) a. Sie hat (vermutlich) einen Stein im Schuh she has (presumably) a stone in the shoe 'She presumably has a stone in her shoe.'

b. \# Als ob sie einen Stein im Schuh hätte. as whether she a stone in the shoe had 'As if she had a stone in her shoe.'

Furthermore, the presumed abductive reasoning in (ii) is fundamentally flawed: obviously, the so-called specific premise depends on the particular extralinguistic context. This amounts to assigning specific extralinguistic information to the premises from which the relevant linguistic meaning-that is, the hypothesis-is inferred. However, the opposite should hold true: the linguistically given meaning must be identified first in order to then derive additional inferences via independently established pragmatic means such as abduction (see Hobbs et al. 1993; Dölling 1997; Maienborn 2003b). 
(6) Ben fährt Rad wie wenn er betrunken wäre.

Ben cycles how if he drunk were

'Ben is cycling as if he were drunk.'

While this approach is intuitively correct, its consequences are barely discussed in more detail. In order to give a refined picture of what is to be captured, I will elaborate on the relevant ontological underpinnings and the role of both the explicit matrix VP and the conditional's antecedent in the following sections.

\subsection{The denotation of V-HCCs from an ontological perspective}

Let us start with a working hypothesis on manner modification in general. A widely accepted intuition is that manner modifiers describe some internal aspect of their target events. One way of specifying this intuition is to conceive of manners as firstorder entities, namely, as particularized properties of events; see Dik (1975), Piñón (2008) and Schäfer (2013). The adverbials beautifully and quickly in (7) then describe the form and the speed manner of Ben's dancing.

(7) Ben is dancing \{beautifully / quickly\}.

In the following, I will survey the consequences of adopting this perspective for $\mathrm{V}$ HCCs and thereby unfold properties of V-HCCs that have gone largely unnoticed so far.

First, it suggests that V-HCCs and their matrix hosts are not related by comparing eventualities as such, but by comparing their individual manners. This is fully in line with Kasper's characterization of V-HCCs used above. The example in (6) could convey that the form of Ben's actual cycling corresponds to the form of his cycling in situations when drunk (for instance, in wiggly lines); alternatively, their speeds could correspond (for instance, very slowly).

Second, particularized properties are bound to the entities they are properties of. Therefore, an individual's property cannot be referentially identical to the property of another individual, while it may be equivalent to it; compare the contrast in (8) from Moltmann (2015).

(8) a. The softness of the first pillow is the same as the softness of the second pillow.

b. \# The softness of the first pillow is the softness of the second pillow.

(Moltmann 2015: ex. (32a, b))

The same holds for manners. Nominal expressions for manners may be said to be equivalent, as suggested by the predicates gleich ('same') or gleichen ('to equal') in (9), but they may not be said to be referentially identical, as suggested by the identity assertion in (10).

(9) a. Die Art, wie Ben arbeitet (wenn er wütend ist), ist die gleiche, wie the manner how Ben works (if he angry is) is the same how Mia arbeitet (wenn sie wütend ist).

Mia works (if she angry is)

'The way Ben works (if he is angry) is equal to the way Mia works (if she is angry).' 
b. Die Art, wie Ben arbeitet (wenn er wütend ist), gleicht der Art, the manner how Ben works (if he angry is) equals the manner wie Mia arbeitet (wenn sie wütend ist). how Mia works (if she angry is) 'The way Ben works (if he is angry) equals the way Mia works (if she is angry).'

(10) \# Die Art, wie Ben arbeitet (wenn er wütend ist), ist die Art, wie the manner how Ben works (if he angry is) is the manner how Mia arbeitet (wenn sie wütend ist).

Mia works (if she angry is)

'The way Ben works (if he is angry) is the way Mia works (if she is angry).'

There is a clear consequence for V-HCCs. The manners of the eventualities that are associated with the worlds selected by the conditional antecedent should also be compared to the manner introduced at the matrix level in terms of equivalence.

Third, adverbials that locate events as wholes in space and time do not contribute to the internal make-up of an event and, thus, do not specify particularized properties of events. As shown by the deviant afterthoughts in (11), V-HCCs cannot receive corresponding temporal or locative readings.

(11) \# Ben bereitet das Huhn zu wie wenn er im Urlaub wäre, nämlich Ben prepares the chicken how if he on vacation were namely \{spät am Abend / im Wohnmobil\}.

\{late in the evening / in the camper\}

'Ben is preparing the chicken as if he were on vacation, namely, \{late in the evening / in the camper\}.'

This supports the assumption that V-HCCs do not compare events as wholes, but specify event-internal properties. ${ }^{4}$ Notably, this constraint is not due to a general conceptual restriction; for instance, one could assert that Ben's cooking is taking place where it usually takes place during his vacation. So, the limited range of readings for V-HCCs should follow from their semantic composition.

Fourth, as is well known, adjectives in German support depictive and resultative readings, as in (12) (see, for instance, Dölling 2003 and Schäfer 2013).

(12) Ben \{fährt nackt Rad / kleidet sich elegant\}.

Ben $\{$ cycles naked / dresses elegant

'Ben is cycling naked / is dressing elegant.'

Crucially, the bearers of the relevant particularized properties are not the events as such, but (entities related to) their participants such as Ben himself or his clothing.

\footnotetext{
${ }^{4}$ The well-formed example in (i) corroborates this approach. The PP does not localize the event as a whole, but the chicken. This gives rise to an event-internal manner-like reading (see Maienborn 2003b for an elaborate discussion of event-internal locatives)

(i) Ben brät das Huhn wie wenn er im Urlaub wäre, nämlich überm Lagerfeuer. Ben roasts the chicken how if he on vacation were namely over the campfire 'Ben is roasting the chicken as if he were on vacation, namely, over the campfire.'
} 
On the one hand, the adjectives thus do not contribute true manner modifiers, but secondary predications. On the other hand, these predications are not independent from, but entwined with their host events. Accordingly, the depictive naked still describes a mode of cycling, although the property does not arise with the event itself, but its participant. Similarly, the resultative elegant conveys that Ben's dressing unfolds in such a way —or, 'mode'—that Ben's clothing receives the property elegant. Therefore, these depictives and resultatives do not contribute random concomitant, or, resulting states of their host events as wholes, but introduce properties that are made accessible via the event-internal structure. This predicts V-HCCs to also obtain corresponding readings, as borne out by the examples in (13) and (14) (= (4)).

(13) Ben fährt Rad wie wenn er betrunken wäre, nämlich nackt.

Ben cycles how if he drunk were namely naked

'Ben is cycling as if he were drunk, namely, naked.'

(14) Ben kleidet sich wie wenn er in die Oper ginge, nämlich elegant.

Ben dresses how if he to the opera went namely elegant

'Ben is dressing as if he went to the opera, namely, elegant.'

The continuations suggest interpretations on a par with (12) above: example (13) says that Ben's appearance is equivalent to his hypothetical appearance in situations where he is cycling drunk, and example (14) says that Ben's resulting clothing is equivalent to his clothing in opera situations.

Depictives may also contribute states that accompany the host event in a purely temporal sense and, thus, lack a mode interpretation. Claudia Maienborn (p. c., supported by an anonymous reviewer) pointed out that V-HCCs prohibit this type of interpretation, as shown by (15). This is as expected, given the assumption that V-HCCs specify particularized event-internal properties. Correspondingly, if contextual information supports a mode-oriented interpretation, the V-HCC gets considerably better, as shown by (16).

(15) a. Ben öffnet nackt die Tür.

Ben opens naked the door

'Ben is opening the door naked.'

b. \# Ben öffnet die Tür, wie wenn er betrunken wäre. $(=(15 a))$

Ben opens the door how if he drunk was

'Ben is opening the door as if he were drunk.'

(16) a. (Context: Speaker and hearer know of Ben that he always undresses when drunk and then doesn't mind opening the door naked:)

b. Ben öffnete die Tür, wie (immer) wenn er betrunken ist - nackt. Ben opened the door how (always) if he drunk is naked 'Ben opened the door as he always does when he is drunk-naked.'

Let me finally note that clausal modifiers such as V-HCCs and their cognate free relatives involve an additional complication. The equivalence analysis argued for above allots separate modifying relations to both the embedded sentence and its matrix host. However, their type of interpretation is not allowed to differ, as shown by (17). (This issue does not arise with adjectives and adverbs, as they only involve one modifying relation.) 
(17) Ben kleidet sich, wie Bella sich kleidet, nämlich elegant. Ben dresses how Bella dresses namely elegant

'Ben dresses as Bella dresses, namely, elegant(ly).'

a. $\checkmark$ 'Ben and Bella dress in an elegant way.' / 'Ben and Bella wear elegant clothes.'

b. \# 'Ben dresses in an elegant way and Bella wears elegant clothes.'

Both relations may be resolved uniformly either to a manner or a predicative reading, as in the paraphrases in (17a), while hybrid options are out, as in (17b). Any analysis should capture this principled constraint, underspecification notwithstanding. ${ }^{5}$

\subsection{The role of the matrix clause VP}

Typically, the matrix VP provides the description of the hypothetical eventuality that hosts the inferred manner. Consider the paraphrase in (18) for (2a) from the introduction, where the conditional's implicit consequent is made explicit by resorting to the linguistic material given at the matrix level.

(18) Ben $_{i}$ fährt Rad wie $e r_{i}$ Rad fahren würde wenn er betrunken wäre Ben cycles how he cycle would if he drunk were

'Ben is cycling as he would cycle if he were drunk.'

Yet, as shown by Kaufmann (1973), Hahnemann (1999), and Bücking (2015) amongst others, the implicit consequent of V-HCCs does not always correspond to the matrix VP. For instance, in (19a), the implicit and the explicit eventuality involve distinct participants; in (19b), the mediating event description does not surface at all.

a. Ben fährt Rad, wie wenn ein Mannequin Rad fährt. Ben cycles how if a mannequin cycles

$\neq$ 'Ben is cycling as he cycles when a mannequin cycles.'

$\approx$ 'Ben is cycling as a mannequin cycles when it cycles.'

b. Ben hustet, wie wenn ein Hofhund bellt.

Ben coughs how if a yard dog barks

${ }^{5}$ V-HCCs can also fulfill a grading function; compare (i) where the explicit afterthought indicates that the V-HCC relates to the degree of resemblance between Paul and Hanno.

(i) Paul ähnelt Hanno, wie wenn er sein Bruder wäre, nämlich sehr. Paul resembles Hanno how if he his brother were namely very 'Paul resembles Hanno as if he were his brother, namely, very much.'

(see Bücking 2015: ex. (50a))

The relation between manners and degrees is a complicated topic of its own; compare Gehrke and Castroviejo (2015), Anderson and Morzycki (2015), and Moltmann (2015). For reasons of space, I will not include a semantics of grading V-HCCs here. However, the common core (and, thus, the prospect of a uniform analysis) is clear: degrees are connected to the internal structure of predicates; grading V-HCCs then build on the equivalence between a given degree and hypothetical degrees. So, in (i), the degree of resemblance between Paul and Hanno is said to be equivalent to the degree of resemblance in situations where both are brothers. 
$\neq$ 'Ben is coughing as he coughs when a yard dog barks.'

$\approx$ 'Ben is coughing. The coughing sounds as it sounds when a yard dog barks.'

(see Bücking 2015: ex. (18a, c); following Kaufmann 1973 and Hahnemann 1999)

The aforementioned scholars exploit these facts to argue against syntactic analyses of V-HCCs in terms of ellipsis. Likewise, the envisaged semantic analysis should not rigidly determine the hypothetical eventualities that host the relevant manner or participant. Instead, the specification should be flexible enough to also be sensitive to context and world knowledge. Notably, the given variability provides another strong argument for the assumption that V-HCCs do not equate events with each other, but rather compare their internal properties.

Let me add a further detail that is not explicitly discussed in the literature, but corroborates the distinction between the hosting event descriptions and their internal properties. The introductory example (2a) seems to just say that Ben's cycling in a specific manner obtains in all worlds in which Ben is drunk; compare the rough approximation in (20). (For ease of presentation, I here assume that the host eventuality is a cycling.)

(20) $\{w$ : Ben is drunk in $w\} \subseteq\{w$ : Ben is cycling in a manner $x$ in $w\}$

However, this is clearly too strong. Intuitively, the specification of a relevant manner should only hold for those worlds where Ben is drunk and is cycling (at the same time), as in (21).

(21) $\{w$ : Ben is drunk and is cycling in $w\} \subseteq\{w$ : Ben is cycling in a manner $x$ in $w\}$

In other words, the semantic set-up should ensure that the host eventuality of the inferred manner is accommodated within the conditional's restrictor. More details on the role of the conditional will be given in the next section.

\subsection{The role of the embedded conditional antecedent}

V-HCCs allow different readings depending on the interpretation of the conditional structure. The following survey provides a systematic approach to this variety in terms of accessibility relations, which, as far as I know, is a new perspective. To foreshadow the analysis, let me note that this variety will be captured in terms of conversational backgrounds as standardly used in modal semantics (see Kratzer 1991a,b). This will render the choice of a particular reading highly context-dependent and comply with the fact that many V-HCCs are formally not bound to one reading. At the same time, factors such as verbal mood, the use of certain adverbials, or the type of V-HCC (see Sect. 6) can be said to systematically constrain the range of potential interpretations.

Extensional and generic reading The example in (22) can be paraphrased as in (23a) or as in (23b). 
(22) Ben fährt Rad, wie wenn er betrunken ist.

Ben cycles how if he drunk is

(23) a. 'Ben is cycling as he always does when he is drunk.'

b. 'Ben is cycling as he usually does when he is drunk.'

The reading in (23a) is extensional in the sense that it involves universal quantification over situations of Ben's being drunk and cycling in the actual world; alternative worlds are not made accessible. By contrast, the reading in (23b) is generic in the sense that the universal quantification does not pertain to the actual world, but to normal or stereotypical worlds. That is, those worlds that involve situations, eventualities, and individuals that are normal or stereotypical from the perspective of the actual world are accessible. ${ }^{6}$ Both readings are possible with wie-V-HCCs in the indicative. They can be made explicit by adverbials such as immer ('always') for the extensional reading and normalerweise ('normally') or typischerweise ('typically') for the generic one:

(24) Ben fährt Rad, wie \{immer / normalerweise / typischerweise \} wenn er Ben cycles how \{always / normally / typically $\}$ if he betrunken ist. drunk is

Counterfactual reading The example in (25a) and its paraphrase in (25b) exemplifies the counterfactual reading.

a. Ben fährt Rad, wie wenn er betrunken wäre. Ben cycles how if he drunk were

b. 'Ben is cycling as he would cycle if he were drunk.'

In terms of the analysis of counterfactuals given in Stalnaker (1968), Lewis (1973), and subsequent work (see for surveys Portner 2009: 247-257 and von Fintel 2011), the universal quantification takes into account only those worlds that are as similar as possible to the actual world, given that the conditional's antecedent is true. It is licensed by verb forms in the counterfactual subjunctive.

It is fairly controversial what the exact semantic or pragmatic contribution by counterfactual conditionals (as opposed to indicative ones) is and how it arises. However, it is widely agreed that counterfactuals do not semantically entail that their antecedent is false; instead, the corresponding impression is due to a pragmatic implicature. This observation carries over to V-HCCs, as shown by (26), where the relevant implicature is canceled by the context.

(26) Ben fährt Rad wie wenn er betrunken wäre. Vielleicht ist er wirklich

Ben cycles how if he drunk were perhaps is he in fact

betrunken.

drunk

'Ben is cycling as if he were drunk. Perhaps he is in fact drunk.'

\footnotetext{
${ }^{6}$ This probably oversimplifies generic quantification; see Krifka et al. (1995) and much subsequent work for the intricacies of determining the appropriate accessibility relations. However, for the present purpose, the given basic characterization should suffice.
} 
Epistemic reading The examples and their paraphrases in (27), (28), and (29) illustrate the epistemic reading. Here, only worlds that are compatible with the speaker's knowledge and belief are accessible; the finite verb is in the indicative. ${ }^{7}$

a. Ben fährt Rad, wie wenn er (gerade) betrunken ist. Ben cycles how if he (currently) drunk is

b. 'Ben is cycling as, in my view, he must cycle if he is (currently) drunk.'

a. Ben schaut Mia an, wie wenn sie ihm (gestern) ihre Liebe Ben looks at Mia how if she him (yesterday) her love gestanden hat. confessed has

b. 'Ben is looking at Mia as, in my view, he must look at her if she confessed her love to him (yesterday).'

a. Die Katze verhält sich, wie wenn sie (gerade) Angst hat. the cat behaves how if it (currently) fear has

b. 'The cat is behaving as, in my view, it must behave if it is (currently) scared.'

This reading differs from the generic and the extensional ones by not involving regularities of someone's behavior, but the speaker's belief given a certain fact in a particular situation. The use of positional temporal adverbials such as gerade ('currently') or gestern ('yesterday') in the conditional antecedent supports this interpretation.

\subsection{Taking stock}

I have argued for the following key traits of V-HCCs introduced by wie: (i) V-HCCs do not contribute an identity relation, but a comparison between event-internal particularized properties via equivalence; the relevant eventive anchors are the explicit matrix event and implicit hypothetical events that are constrained by the given conditional antecedent. (ii) The event-internal particularized property can be either borne by the event itself, which yields the canonical manner interpretation, or by (entities related to) the event's participants, which yields predicative readings. Notably, no crossing of a predicative and a manner interpretation is allowed. (iii) The implicit hypothetical events should invariably feed the restrictor licensed by the given conditional antecedent. They are typically, but not obligatorily, of the same type as the explicit matrix event. (iv) The quantification over hypothetical scenarios is constrained by different kinds of accessibility relations, giving rise to extensional, generic, counterfactual, and epistemic readings.

\section{S-HCCs with wie}

Many scholars distinguish between adverbal hypothetical comparison clauses, that is, $\mathrm{V}-\mathrm{HCC}$ as discussed above, and corresponding sentence adverbials, S-HCCs in the following (see Kasper 1987; Hahnemann 1999; Pasch et al. 2003; Fabricius-Hansen

\footnotetext{
${ }^{7}$ The epistemic reading is brought out most clearly by als-HCCs with verb-first position and the verb form in the reportative subjunctive; see Sect. 6.
} 
2007; Pauly 2013; Demske 2014; Bücking 2015). The authors, however, only scratch the surface of the semantic underpinnings of the distinction. Pauly, Demske, and Bücking focus on syntactic issues; see below. Hahnemann (1999: 216) states that S-HCCs pattern with 'sentence comparisons'; Pasch et al. (2003: 622) and, similarly, Kasper (1987: 135, 137) argue that S-HCCs involve the 'equalization' or 'identification of states of affairs.' But since explicit semantic descriptions are missing, the exact status of such a sentence-based equality or identity remains unclear; for instance, as will become apparent shortly, a naive identity relation between states of affairs falls short of the relevant facts.

First, any adequate analysis should address structural reasons for the semantic distinction between S-HCCs and V-HCCs. A correlation between form and interpretation is highly likely given that V-HCCs and S-HCCs are linked to their matrix hosts in fairly different ways. Various diagnostics show that V-HCCs occupy integral structural slots of their host sentences while S-HCCs are dependent, but syntactically unintegrated clauses; see Pauly (2013), Demske (2014), and Bücking (2015) for a discussion of HCCs and Reich and Reis (2013) for a general survey of clausal (non-)integration. For instance, S-HCCs cannot be within the scope of sentence negation, have a separate focus-background structure, and prohibit the correlate $s o$ in the middlefield of the host clause, as in (30). By contrast, V-HCCs are affected by sentence negation, do not have a separate focus-background structure, and allow so, as in $(31)$.

a. * Hanno ernährt sich nicht von Fertigpizzen, wie wenn er nicht Hanno feeds REFL not on pre-made pizzas how if he not kochen könnte. Vielmehr ist er einfach nur ein großer Liebhaber cook could rather is he simply only a big lover von solchen Fertiggerichten!

of such pre-made dishes

'Hanno does not live on pre-made pizzas as if he could not cook. He rather just likes pre-made dishes a lot.'

b. i. * Hanno ernährt sich von Fertigpizzen, wie wenn er nicht Hanno feeds REFL on pre-made pizzas how if he not KOCHen könnte.

cook could

'Hanno lives on pre-made pizzas as if he could not COOK.'

ii. Hanno ernährt sich von FERtigpizzen, wie wenn er nicht Hanno feeds REFL on pre-made pizzas how if he not KOCHen könnte.

cook could

'Hanno lives on PRE-made pizzas, as if he could not COOK.'

c. * Hanno ernährt sich so von Fertigpizzen, wie wenn er nicht Hanno feeds REFL so on pre-made pizzas how if he not kochen könnte.

cook could

'Hanno lives on pre-made pizzas in a way as if he could not cook.'

(see Bücking 2015: ex. (26d), (26b), (26a)) 
(31) a. Mia hat die Gans nicht angeschaut, wie wenn sie Mitleid mit ihr Mia has the goose not looked at how if she pity with it hätte. Vielmehr freute sie sich schon sehr auf das had rather looks forward she REFL already very to the anstehende Festmahl! upcoming feast

'Mia did not look at the goose as if she felt sorry for it. She was rather looking forward to the upcoming feast.'

b. Mia hat die Gans angeschaut, wie wenn sie MITleid mit ihr hätte. Mia has the goose looked at how if she pity with it had 'Mia looked at the goose as if she felt SORry for it.'

c. Mia hat die Gans so angeschaut, wie wenn sie Mitleid mit ihr hätte. Mia has the goose so looked at how if she pity with it had 'Mia looked at the goose in a way as if she felt sorry for it.'

(see Bücking 2015: ex. (24d), (24b), (24a))

Hence, while the semantics of V-HCCs should follow from their adjunction to the verbal layer, the semantic contribution of S-HCCs should be linked to their having scope over the matrix proposition as a whole. ${ }^{8}$

Second, S-HCCs are sensitive to the same accessibility relations as V-HCCs are; compare (32)-(34) for illustration.

(32) Extensional and generic reading

a. Bella schweigt, wie (immer / normalerweise) wenn sie beleidigt ist. Bella keeps silent how (always / normally) if she offended is

b. 'Bella is keeping silent, as is \{always / normally\} the case when she is offended.'

(33) Counterfactual reading

a. Bella lächelt selig, wie wenn das Pferd nicht aus Stoff wäre, Bella smiles blissfully how if the horse not of cloth were sondern aus Fleisch und Blut.

but of flesh and blood

b. 'Bella is smiling blissfully, as would be the case if the horse were not made of cloth, but flesh and blood.'

\footnotetext{
${ }^{8}$ Notably, S-HCCs do not relate to speech acts. While, for instance, weil-clauses are well known for speechact related readings, S-HCCs do not seem to allow them; compare (i):

(i) a. Ist Bella bei der Arbeit, weil ihr Auto ist weg?

is Bella at the work because her car is away

$\approx$ 'I am asking whether Bella is at work because her car is missing.'

b. * Ist Bella bei der Arbeit, wie wenn es mich interessieren würde?

is Bella at the work how if it me interest would

$\neq$ 'I am asking whether Bella is at work as if it were of interest to me.'

This might be different for a third type of HCCs, namely independent ones, which are not discussed in the present paper; see Sect. 7 for the challenge they pose.
} 
(34) Epistemic reading

a. Hanno schaut Bella glücklich an, wie wenn sie ihm endlich ihre Hanno looks at Bella happily how if she him finally her

Liebe gestanden hat. love confessed has

b. 'Hanno looks at Bella happily, as, in my view, it must be the case if she has finally confessed her love to him.'

Third, the relationship between the matrix proposition and the S-HCC's silent consequent is not identity, but equivalence. The counterfactual variant of (32) in (35) and the paraphrases that make its meaning explicit in (36a) and (36b) provide evidence.

Bella schweigt, wie wenn sie beleidigt wäre.

Bella keeps silent how if she offended were

'Bella is keeping silent, as if she were offended.'

(36) a. Bella schweigt; ebenso wäre es, wenn Bella beleidigt wäre.

Bella keeps silent the same were it if Bella offended were

'Bella is keeping silent; it would be the same if Bella were offended.'

b. Bella schweigt; eine Situation dieser Art läge auch vor, wenn Bella keeps silent a situation of this kind existed also if

Bella beleidigt wäre.

Bella offended were

'Bella is keeping silent; a situation of this kind would also exist if Bella were offended.'

Both descriptions show that wie has a bearing on the semantics of S-HCCs that goes beyond identification. Namely, they build on the adverb ebenso ('the same') and the nominal predicate eine Situation dieser Art ('a situation of this kind'), respectively. Both options explicitly point to comparison situations; this is clear evidence for the claim that the situations involved in S-HCCs are not referentially identical to those given at the matrix level, but are equivalent to them in some relevant way. From a compositional perspective, this is a welcome result since the equivalence function associated with wie in V-HCCs is thereby found in S-HCCs as well. Notably, an identifying anaphoric link to propositions or facts is usually established by pro-forms such as das ('this'/'that') or was ('which'). In fact, S-HCCs allow an additional anaphoric link to the matrix proposition via das, as in (37). This lends further support to the proposed distinction between identification and equivalence.

(37) [Bella schweigt $]_{i}$, wie wenn das ${ }_{i}$ entschuldbar wäre.

Bella keeps silent how if that excusable were

'Bella is keeping silent, as if that were excusable.'

Taking stock, an appropriate analysis of S-HCCs with wie should capture the following key characteristics: (i) S-HCCs share with V-HCCs both the contribution of an equivalence relation instead of an identity function and the sensitivity to various kinds of accessibility relations. (ii) S-HCCs differ from V-HCCs in not comparing events, but broader situational settings. This difference is rooted in a structural difference: while V-HCCs are integrated into their matrix hosts, S-HCCs are not. 


\section{Analysis: V-HCCs with wie}

In order to flesh out the interpretation of wie-V-HCCs, I will capitalize on the following independently motivated assumptions.

First, the analysis follows the treatment of modals and conditionals in terms of doubly relative modality, as in Kratzer (1991a,b); more recent critical appraisals are provided by Portner (2009) and Hacquard (2011). Kratzer (1991a) interprets modals in relation to two interacting conversational backgrounds that are conceived of as functions from worlds to propositions: the modal base $f$ renders those worlds accessible from a world $w$ that are compatible with certain facts in $w$. The ordering source $g$ assigns ideals to a world $w$ relative to which the accessible worlds are ordered. Kratzer's perspective on modality is closely related to her analysis of conditionals in Kratzer (1991b). Crucially, the conditional's antecedent is said to restrict a modal operator. The antecedent contributes a fact to the modal base and thereby restricts the set of accessible worlds. If the consequent lacks an explicit operator, a silent universal modal ( $=\mathrm{OP}_{\forall}$ in the following) is licensed; see (38), which exemplifies an epistemic reading.

(38) a. If my hen has laid eggs today, then the Cologne cathedral will collapse tomorrow morning.

b. $\mathrm{OP} \forall$ [my hen has laid eggs today; the Cologne Cathedral will collapse tomorrow]

(see Kratzer 1991a: ex. (1) and (32))

Second, the semantic representations will be spelled out according to situation semantics in the sense of Kratzer (1989, 2010); see Portner (2009: 214-220) for the following recapitulation: situations are considered basic entities that can have parts; $s^{\prime} \leq s$ stands for ' $s$ ' is a part of $s$ '. Different types of situations are distinguished: "maximal situations," not being part of any other situation, are worlds. The example in (39) can be used to introduce further types of situations.

Josephine flew an airplane.

(Portner 2009: ex. (268))

For the case at hand, "minimal situations" are the smallest possible situations that contain a flying of an airplane by Josephine. "Exemplifying situations" are possible combinations of minimal situations, be they spatio-temporally connected or not; "counting situations" are maximal spatio-temporally linked exemplifying situations. If Josephine flew an airplane for two hours exactly twice, there are two counting situations. Intuitively, this corresponds to quantification over events in the sense of Davidson (1967) (given some adequate counting criterion). In fact, following Kratzer (2010), I will use event predications such as ' $\exists e\left[\mathrm{fly}^{\prime}(e, x, y)\right]$ ' as a handy way of saying that there is a maximal spatio-temporally linked event of flying $y$ by $x$.

Third, in order to model equivalence relations, the proposal builds upon the analysis of similarity in Umbach and Gust (2014), where similarity is conceived of as equivalence relative to attribute spaces. Umbach and Gust are concerned with the demonstrative so ('so' / 'such') in examples such as (40a). Its meaning is represented as in (40b). 
(40) a. (Speaker points to a car in the street:)

So ein Auto hat Anna.

such a car has Anna

'Anna has such a car.'

b. $\exists x \cdot \operatorname{sim}^{\prime}\left(x, x_{\text {target }}, F\right) \wedge \operatorname{car}^{\prime}(x) \wedge$ own'(Anna, $\left.x\right)$

(see Umbach and Gust 2014: ex. (14a, e))

Their analysis captures that the so-phrase simultaneously functions as a deictic and a modifying expression: the target of the pointing gesture and the relevant DP-referent are not said to be identical, but similar to each other. Furthermore, similarity is relativized to so-called attribute spaces $F$; this renders similarity sensitive to conceptually based constraints. With regard to adnominal so, for instance, Umbach and Gust argue that only conceptual dimensions that may identify subkinds of the given head noun (that is, fuel type, door number, etc. in the case of $c a r$ ) are relevant. Finally, Umbach and Gust provide a definition of similarity in terms of equivalence relative to attribute spaces $F$; these attribute spaces are made accessible for truth-conditions via so-called classifying functions $p^{*}$. Compare the definition in (41).

$$
\operatorname{sim}^{\prime}(x, y, F) \text { iff } \forall p^{*} \in C(F): p^{*}\left(\mu_{F}(x)\right)=p^{*}\left(\mu_{F}(y)\right)
$$

(see Umbach and Gust 2014: ex. (37))

According to (41), generalized measure functions $\mu_{F}$ map entities to values in attribute spaces. ${ }^{9}$ Let, for instance, $\mu_{\text {FUEL-TYPE }}$ map $x$ to DIESEL and $y$ to GASOLINE. Two entities are similar relative to $F$ iff the application of every classifying function $p^{*}$ from the set of classifying functions $C(F)$ to the relevant values in the attribute spaces yields the same truth-value. In the given scenario, $x$ and $y$ are not similar relative to the fuel-type attribute space because the classifying functions diesel* and gasoline* yield different truth-values for them (for instance, $\operatorname{diesel}^{*}\left(\mu_{\text {FUEL-TYPE }}(x)\right)=\operatorname{diesel}^{*}($ DIESEL $)=1$, whereas $\operatorname{diesel}^{*}\left(\mu_{\text {FUEL-TYPE }}(y)\right)=$ diesel $^{*}($ GASOLINE) $=0)$. Notably, this system allows for a flexible specification of the relevant level of granularity: if $C(F)$ contains only combustion engine* and, thus, yields a more coarse-grained grid on the attribute space, $x$ and $y$ would count as similar in the given scenario.

Fourth, and finally, I take the interpretation of modifiers to be sensitive to whether the modifier attaches at the head or the phrasal level. The general idea is that headadjacent modifiers have access to the internal structure of their targets and, thus, license mediation by conceptual knowledge, while modifiers at the phrasal level relate to their targets holistically; see Maienborn (2001, 2003b), Maienborn et al. (2016), and Schäfer (2013) for different types of modifiers in the verbal domain, and Bücking (2012) for the nominal domain. The aforementioned authors capture this sensitivity in terms of (different versions of) a structure-sensitive modification template. Here, I will rely on MOD* as given in (42). ${ }^{10}$

\footnotetext{
${ }^{9}$ These functions are multidimensional generalizations of measure functions as used in degree semantics.

${ }^{10}$ This basically corresponds to a polymorphic variant of Schäfer (2013: ch. 7, ex. (39)), enriched by circumstantial and resultative properties. Two technical comments are in order here: first, the functor is polymorphic because it must allow non-referential arguments of the target constituent to pass unchanged on to
} 
a. $\mathrm{MOD}^{*}=\lambda Q \lambda P \ldots \lambda x . P(\ldots)(x) \wedge R(x, v) \wedge Q(v)$

b. Condition on the application of MOD*:

If MOD* is applied in a structural environment of categorial type $\mathrm{X}$, then $R=$ internal-property' $^{\prime}$ (where internal-property' is an underspecified parameter for a manner, circumstance, or result function), otherwise (that is, in an XP-environment) $R=$ identity' $^{\prime}$

The example in (43a) and its representation in (43b) (adapted from Piñón 2008: ex. (14) and Schäfer 2013: ch. 7, ex. $(5,6)$ ), exemplify the derivation of a manner interpretation via MOD*: a function for form manners maps the dancing to an individual form manner, which, in turn, is described as beautiful.

a. dass Ben $[V$ schön tanzt $]$
that Ben $[V$ beautifully dances $]$
'that Ben is dancing beautifully'

b. $\exists e\left[\operatorname{dance}^{\prime}(e) \wedge \operatorname{ag}^{\prime}(e\right.$, Ben $) \wedge \operatorname{manner}_{f o r m}{ }^{\prime}(e, m) \wedge$ beautiful $\left.^{\prime}(m)\right]$

The resultative reading in (44a) follows form using a result function that maps the dancing to an individual form result, as in (44b). The predication is secondary, as the resultative particularized property is borne by (an entity related to) an eventparticipant, here, Ben's clothing as it results from the dressing.

a. dass sich Ben [ $V$ elegant kleidet]

that Ben [ $v$ elegant dresses]

'that Ben dresses elegant'

b. $\exists e\left[\operatorname{dress}^{\prime}(e) \wedge \operatorname{ag}^{\prime}(e\right.$, Ben $) \wedge \operatorname{result}_{\text {form }}(e, r) \wedge$ elegant $^{\prime}(r)$

$\wedge \operatorname{bearer}\left(r, \iota c\right.$ [clothing-of' $(c$, Ben $\left.\left.\left.) \wedge \operatorname{result}^{\prime}(e, c)\right]\right)\right]$

I will now show step by step how to derive the interpretation of V-HCCs from these ingredients. Sect. 4.1 details the internal semantics of V-HCCs, while Sect. 4.2 is concerned with the external link to their matrix clauses.

\subsection{The internal semantics of V-HCCs: Interpreting wie and the embedded conditional}

\subsubsection{V-HCCs with wie as free relatives}

Before putting the compositional machinery to work, a plausible structural basis for interpreting V-HCCs must be determined. Bücking (2015) argues for treating wie-VHCCs as integrated free relatives. A greatly simplified structure for the wie wennclause in (45a) is given in (45b). ${ }^{11}$

\footnotetext{
the modified resulting expression; see Maienborn (2001) and Bücking (2012). Accordingly, '..' stands for an optional series of $\lambda$-bound arguments. Second, it is a notoriously difficult question of whether one should (existentially) bind the additional mediating variable $v$, or not; Schäfer does so while Maienborn considers it a free variable. I follow Maienborn here without, however, deriving any crucial consequences from this decision.

${ }^{11}$ The original proposal is spelled out in terms of Sternefeld's (2006) feature-based syntactic framework. Since the corresponding feature-driven details are not crucial for the semantic derivation, I leave them out here. The wenn-clause is part of the VP; compare Sect. 4.2 for the question of how adverbial clauses are syntactically integrated at the right edge.
} 
(45) a. (Ben fährt Rad,) wie wenn er betrunken ist. (Ben cycles) how if he drunk is '(Ben is cycling) as he does when he is drunk.'

b.

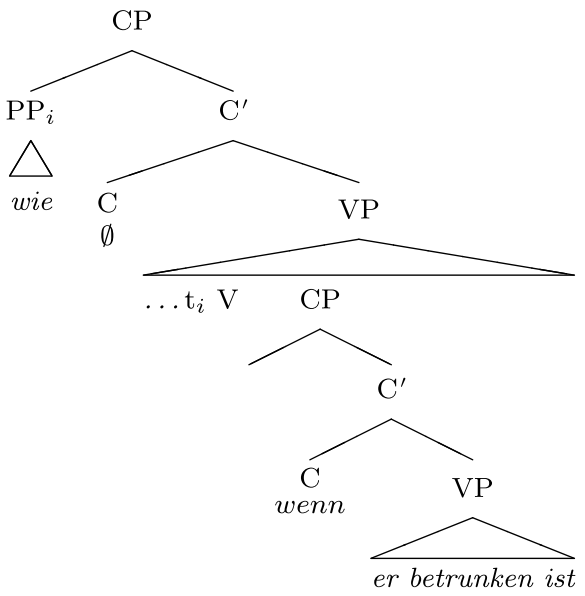

(see Bücking 2015: ex. (41))

Two aspects of this analysis are crucial for deriving the meaning of wie-V-HCCs: first, wie is treated as a moved $w h$-constituent accompanied by semantic information, analogously to ordinary free relatives. While, for instance, wo ('where') bears a spatial meaning, wie can thus be considered the compositional anchor for comparison; see below for details. Second, wie's VP basis is special: it is (phonologically) empty except for the wenn-clause. This wenn-clause is an integrated postfield constituent that must be licensed by a silent V head; in other words, the explicit wenn-antecedent gives reason to assume a silent consequent. As a consequence, the VP is not lexically given and, thus, to be specified by pragmatic means. Its identification with the given matrix event description (that is, Ben's cycling in (45)) is certainly a highly plausible option; crucially, however, the structure does not require it.

The following observations (mostly drawn from Bücking 2015) provide independent evidence for the given structure: first, the presumed VP can be made explicit as in (46a); recall as well the examples in (24), where adverbials such as immer ('always') are indicative of a silent consequent. Second, as equatives such as (46b) show, the equivalence relation brought in by V-HCCs is not an effect of the structure as a whole, but given by wie in a semantically transparent way. Third, wie can be extended by modifications such as ungefähr ('roughly'), as in (46c), which supports its phrasal analysis.

(46) a. Ben fährt Rad, wie er Rad führe, wenn er betrunken wäre. Ben cycles how he cycled if he drunk were 'Ben is cycling as he would cycle if he were drunk.'

b. Ben ist so betrunken wie Mia.

Ben is so drunk how Mia

'Ben is as drunk as Mia.' 
c. Martha fährt Rad [ $P P$ ungefähr wie] wenn sie betrunken wäre.

Martha cycles [PP roughly how] if she drunk were

'Martha is cycling as she roughly would cycle if she were drunk.'

(see Bücking 2015: ex. (60))

The fourth argument is a bit more intricate: peculiarly, wie-HCCs do not allow verb-first conditional antecedents (recall (2c) from the introduction). At first glance, this comes as a surprise because verb-first antecedents are semantically fairly transparent in contemporary German. However, as argued for by Reis and Wöllstein (2010), they are obligatorily non-integrated and, thus, not related to the matrix VP. Bücking conjectures that verb-first conditionals cannot help identify the silent VP and are, thus, ruled out in HCCs with wie. Notably, this principled explanation for the striking distributional pattern is based on a structure that enforces the identification of a silent verbal head, as in (45b). Conversely, wie can be combined with other adverbial clauses that are potential licensers of a silent VP, such as the temporal ones in (47). While a discussion of their semantics is beyond the scope of this paper, their being possible provides further evidence for a largely regular combinatorics of wie.

(47) Ben freut sich wie \{als er noch ein Kind war / nachdem er die Prüfung

Ben rejoices how \{when he still a child was / after he the exam bestanden hatte .

passed had

'Ben is rejoicing as he did $\{$ when he was still a child / after having passed the exam $\}$.'

One significant puzzle remains. As pointed out by an anonymous reviewer and also briefly mentioned in Bücking (2015: 303), there are no HCCs introduced by wh-words different from wie, as shown by (48). This is surprising, given that their explicit counterparts in (49) are grammatical.

a. * Mia sammelt Pilze wo wenn Ben Pilze sammelt.
Mia gathers mushrooms where if Ben mushrooms gathers (see Bücking 2015: ex. (87b))

b. * Ben sammelt was (immer) wenn er im Wald ist. Ben gathers what (always) if he in the wood is

a. Mia sammelt Pilze wo (auch) Ben Pilze sammelt, wenn Mia gathers mushrooms where (also) Ben mushrooms gathers if er Pilze sammelt.

he mushrooms gathers

'Mia gathers mushrooms where also Ben gathers mushrooms if he gathers mushrooms.'

(see Bücking 2015: ex. (87a))

b. Ben sammelt was er immer sammelt, wenn er im Wald ist. Ben gathers what he always gathers if he in the wood is 'Ben is gathering what he always gathers when he is in the wood.'

I suggest the following tentative answer to this challenge: as argued for in Sect. 2.1, wie relates to event-internal particularized properties that do not exist independently 
from their host events. This intimate relation is a plausible reason for why wie indicates the existence of an event and, thus, can identify a corresponding head. By contrast, wh-words such as wo ('where') or was ('what') relate to entities that exist independently from the events they contribute to. This independence is a plausible reason for why they cannot license a silent eventive head. I leave a full-fledged account of the relevant constraints to further research. For the time being, the upshot is that only the interplay of an integrated adverbial on the one hand and wie as a marker for particularized properties on the other supports the structure in $(45 \mathrm{~b}) .^{12}$

\subsubsection{The compositional derivation of the internal semantics of V-HCCs}

Given the assumptions made above, the interpretation of the wenn-clause within its matrix consequent is now straightforward; compare (50). The silent VP lacks an explicit operator. Therefore, the antecedent contributes a fact to the modal base of a silent universal modal quantifier. The particular formulation in the spirit of situation semantics builds upon the analysis of quantificational modals in Portner (2009: 274); see Menéndez-Benito (2013) as well. ${ }^{13}$

$$
\begin{aligned}
& \llbracket \mathrm{OP} \forall \ldots \mathrm{V} \text { wenn er betrunken ist } \rrbracket^{w, f, g} \\
& =1 \text { iff } \forall w^{\prime} \\
& \quad\left[w^{\prime} \in \operatorname{Best}_{g(w)}\left(\bigcap\left(f(w) \cup\left\{\left\{w^{\prime \prime}: \exists e^{\prime \prime}\left[e^{\prime \prime} \leq w^{\prime \prime} \wedge \operatorname{drunk}^{\prime}\left(e^{\prime \prime}, \text { Ben }\right)\right]\right\}\right\}\right)\right) ;\right. \\
& \left.\quad \forall e\left[e \leq w^{\prime} \wedge \operatorname{drunk}^{\prime}(e, \operatorname{Ben}) ; \exists s \exists e^{\prime}\left[e \leq s \wedge e^{\prime} \leq s \wedge \llbracket \ldots \mathrm{V} \rrbracket\left(e^{\prime}\right)\right]\right]\right]
\end{aligned}
$$

In prose: the fragment in (50) is true in $w$ relative to $f$ and $g$ iff the following holds for all $g$-best worlds $w^{\prime}$ in the set of $f$-accessible worlds that contain an event of Ben's being drunk: all events $e$ that are part of $w^{\prime}$ and are an event of Ben's being drunk can be extended to a situation $s$ that contains a V-event.

Notably, the analysis makes a first welcome prediction. As assumed for conditionals based on an implicit operator, a necessity modal is introduced. This is in line with the fact that the various readings $\mathrm{V}-\mathrm{HCC}$ give rise to involve universal quantification; see Sect. 2.3 and the following discussion.

\footnotetext{
${ }^{12}$ One reviewer points out that wie-clauses may also function as noun-like arguments, as in (i), and asks whether (V-)HCCs allow this as well. (ii) shows that they do not.
}

(i) Ben mag, wie Mia sich bewegt.

Ben likes how Mia moves

'Ben likes how Mia moves.'

(ii) *Ben mag, wie wenn sich Mia bewegt.

Ben likes how if Mia moves

I offer the following explanation: plausibly, wie needs at least one explicit anchor for the relevant particularized property. In (i), this is given by the verb in the subordinate clause. In (ii), however, there is no adequate anchor: the predicate sich bewegen ('move') is part of the conditional clause and, thus, too deeply embedded, while the matrix predicate mögen ('like') is the argument-taking functor and, thus, hierarchically too high. This contrasts with modifying V-HCCs where the matrix clause does contribute a relevant event for the particularized property. A full-fledged discussion is beyond the scope of this paper; in particular, one has to clarify what kind of (internal) structure wie-clauses such as in (i) have and to what extent it conforms to the one of adverbial free relatives.

${ }^{13}$ As mentioned above, I will use event predications in order to capture what they call counting situations. 
The next step concerns wie's semantic role. The given structure suggests a composition that follows the interpretation of ordinary free relative clauses. Their semantics is a complicated topic in its own right; see, for instance, Caponigro (2004) or Hinterwimmer (2013). While the discussion in the literature is mostly concerned with DP-like free relatives (which are introduced by, for instance, wer ('who') or was ('what')), Caponigro also sketches an analysis of PP-like adverbial free relatives such as the ones in (51).
a. Capt. Kirk went (to) [ ${ }_{C P}$ where $_{1}$ Mr. Spock went (to) $\left.t_{1}\right]$. 'Capt. Kirk went to the place(s) Mr. Spock went to.'
b. Capt. Kirk went (to) [ $C P$ where ${ }_{1}$ no man had gone (before) (to) $t_{1}$ ]. 'Capt. Kirk went to a place no man had gone to (before).'

$\lambda x_{1}$ :place $\left(x_{1}\right)$. went $^{\prime}\left(\right.$ to $\left.^{\prime}\left(x_{1}\right)\right)($ spock$)$

(see Caponigro 2004: ex. (29), (31))

According to the denotation in (52), the free relative CPs in (51) basically denote sets of places where Mr. Spock went. This follows from standard $\lambda$-abstraction over the internal variable associated with the trace (motivated by the movement of where, in spirit similar to predicate abstraction as in Heim and Kratzer 1998), and from a presupposition to the effect that $x_{1}$ must be a place (motivated by the content of where). By using one of two type-shifting rules - namely, "iota" or "existential closure"-this set is mapped either to the maximal place Mr. Spock went to (giving rise to singular or plural definite readings, as in (51a)) or to a non-maximal one (giving rise to an existential reading, as in (51b)). ${ }^{14}$ Caponigro suggests an analogous treatment of free relative clauses with how using manners instead of places; however, this suggestion is not spelled out in detail. I see the following obstacles for an all too simple transfer. First, as argued for in Sect. 2.1, the manner of the matrix event and the manner of the embedded event must not be identical; this, however, would follow from abstracting over a manner variable, analogously to (52) (where it is correct, since, in (51), both the matrix clauses and the free relative clauses involve the very same places). Second, as also argued for in Sect. 2.1, wie-clauses should, besides manner interpretations, license predicative readings, which casts doubt on lexically associating how and wie with manners. Third, Caponigro's analysis does not pay attention to the verb-adjacency of manner modifiers; it would be desirable to make use of this peculiarity at the syntax-semantics interface. Finally, the proposal involves two silent prepositions - one on top of the base position of where within the free relative clause, another one on top of the free relative as a whole-one argument being that these implicit prepositions can be made explicit (see Caponigro and Pearl 2009 for further discussion). However, (at least) wie in German strictly forbids any explicit preposition. For instance, (53) with a preposition on top of the free relative clause is clearly ungrammatical.

$$
\begin{aligned}
& \text { * Ben fährt Rad }\{\text { in / auf / zu }\} \text { wie }_{i} \text { Mia } t_{i} \text { Rad fährt. } \\
& \text { Ben cycles \{in / on / to }\} \text { how }_{i} \text { Mia } t_{i} \text { cycles } \\
& \text { 'Ben is cycling as Mia is cycling.' }
\end{aligned}
$$

\footnotetext{
${ }^{14}$ The second option is said to only apply if iota cannot apply for independent reasons, for instance, because no plausible maximal element exists, as in (51b).
} 
This observation speaks against an application of Caponigro's syntactic structure to German wie and argues in favor of an approach with an inherently prepositional whpronoun (as assumed for wie in the parsimonious structure given in (45b)).

What could an alternative analysis for examples such as (54) look like?

(54) Ben fährt Rad, wie ${ }_{i}$ [VP Mia $t_{i}$ Rad fährt].

Ben cycles how $_{i}\left[{ }_{V P}\right.$ Mia $t_{i}$ cycles]

'Ben is cycling as Mia is cycling.'

I consider wie a plausible lexical anchor for equivalence. Accordingly, I assume that wie, in its base position, introduces a predicate of equivalence as in (55), which denotes the set of $y$ that are equivalent to some assignment-dependent entity $a(i)$. Note that the same analysis can plausibly be given for wie's deictic counterpart in (56).

$\llbracket \mathrm{wie}_{i} / \mathrm{so}_{i} \rrbracket^{a}=\lambda y \cdot \operatorname{sim}^{\prime}(y, a(i), F)$

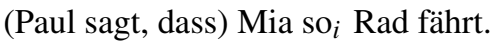

Paul says that Mia so cycles

'(Paul says that) Mia cycles this way.'

This captures without further ado the PP-like predicate interpretation of wie's base and $s o$, and enables the regular application of MOD*, as shown by (58) for (57). Since wie and so are projected in a $\mathrm{V}$-adjacent position, MOD* licenses the introduction of a free variable $v$ that is linked to the V-event via $R$. The integration of the subject and the existential binding of the event argument (including its substitution by the more transparent variable $e$ ) yield (59).

[VP Mia $\left\{t_{i} / \mathrm{so}_{i}\right\} \operatorname{Rad}$ fährt]

$$
\begin{aligned}
& \text { a. } \llbracket \operatorname{Rad} \text { fährt } \rrbracket=\lambda y^{\prime} \lambda e^{\prime} . \operatorname{cycle}^{\prime}\left(e^{\prime}\right) \wedge \operatorname{ag}^{\prime}\left(e^{\prime}, y^{\prime}\right) \\
& \text { b. } \operatorname{MOD} *\left(\llbracket\left\{t_{i} / \mathrm{so}_{i}\right\} \rrbracket^{a}\right) \\
& =[\lambda Q \lambda P \ldots \lambda x . P(\ldots)(x) \wedge R(x, v) \wedge Q(v)]\left(\lambda y \cdot \operatorname{sim}^{\prime}(y, a(i), F)\right) \\
& =\lambda P \ldots \lambda x . P(\ldots)(x) \wedge R(x, v) \wedge \operatorname{sim}^{\prime}(v, a(i), F) \\
& \text { c. } \llbracket\left\{t_{i} / \mathrm{so}_{i}\right\} \operatorname{Rad} \text { fährt } \rrbracket^{a} \\
& =\left[\mathrm{MOD}^{*}\left(\llbracket\left\{t_{i} / \mathrm{SO}_{i}\right\} \rrbracket^{a}\right)\right](\llbracket \operatorname{Rad} \text { fährt } \rrbracket) \\
& =\left[\lambda P \ldots \lambda x . P(\ldots)(x) \wedge R(x, v) \wedge \operatorname{sim}^{\prime}(v, a(i), F)\right] \\
& \left(\lambda y^{\prime} \lambda e^{\prime} \cdot \operatorname{cycle}^{\prime}\left(e^{\prime}\right) \wedge \operatorname{ag}^{\prime}\left(e^{\prime}, y^{\prime}\right)\right) \\
& =\left[\lambda P \lambda y \lambda x . P(y)(x) \wedge R(x, v) \wedge \operatorname{sim}^{\prime}(v, a(i), F)\right] \\
& \left(\lambda y^{\prime} \lambda e^{\prime} . \operatorname{cycle}^{\prime}\left(e^{\prime}\right) \wedge \operatorname{ag}^{\prime}\left(e^{\prime}, y^{\prime}\right)\right) \\
& =\lambda y \lambda x \cdot \operatorname{cycle}^{\prime}(x) \wedge \operatorname{ag}^{\prime}(x, y) \wedge R(x, v) \wedge \operatorname{sim}^{\prime}(v, a(i), F)
\end{aligned}
$$

$$
\exists e\left[\operatorname{cycle}^{\prime}(e) \wedge \operatorname{ag}^{\prime}(e, \mathrm{Mia}) \wedge R(e, v) \wedge \operatorname{sim}^{\prime}(v, a(i), F)\right]
$$

In the deictic variant, the assignment-dependent entity $a(i)$ - that is, the entity of comparison-cannot be subject to local binding, but must be taken from the extralinguistic context. For instance, $v$ could be said to be equivalent to the manner of an event the speaker is pointing to. With the free relative clause, however, the assignment-dependent entity is sensitive to the $\lambda$-abstraction that is triggered by the moved binding relative pronoun; namely, the assignment-dependent entity must be identified with the $\lambda$-abstracted variable (see the Predicate Abstraction Rule in Heim and Kratzer 1998: 186). As a result, the whole free relative in (60a) receives the denotation in (60b). 

a. wie $_{i}\left[v P\right.$ Mia $t_{i}$ Rad fährt]
b. $\lambda x \exists e\left[\operatorname{cycle}^{\prime}(e) \wedge \operatorname{ag}^{\prime}(e\right.$, Mia $\left.) \wedge R(e, v) \wedge \operatorname{sim}^{\prime}(v, x, F)\right]$

Notably, the syntactic movement pertains to wie as a whole while the semantically relevant abstraction affects only one part of its meaning, namely, the entity of comparison; correspondingly, the equivalence predication is interpreted in situ. I consider this dissociation not particularly surprising, given that pronominal prepositional phrases are quite generally subject to 'pied-piping' in German; see, for instance, (61a) where movement includes the preposition although the semantics would need its interpretation in situ, as in the ungrammatical counterpart in (61b).
a. der Ballsaal, $[P P \text { in dem }]_{i}$ Peter $t_{i}$ tanzte the ballroom $[P P \text { in that }]_{i}$ Peter $t_{i}$ danced the ballroom where Peter was dancing
b. * der Ballsaal, $\operatorname{dem}_{i}$ Peter $\left[P P\right.$ in $\left.t_{i}\right]$ tanzte the ballroom that ${ }_{i}$ Peter $\left[P P\right.$ in $\left.t_{i}\right]$ danced

For reasons of space, I will not be able to discuss the syntax-semantics interface of pied-piping in German; see Sternefeld (2006: 395-408) for its structural analysis within a feature-driven framework. I will not venture either upon an appropriate semantic and/or syntactic decomposition of wie into a component for the equivalence relation and a component for the entity of comparison (this is needed for a parallel analysis to (61a), where the locative relation and the location are decomposed into a preposition and a determiner phrase). However, the analogy should suffice to indicate that the proposed semantic composition is not ad hoc.

The analysis avoids the problems of Caponigro's suggestion: Since $v$ is related to the given event via $R$, the resulting logical form does not unequivocally settle a manner interpretation (see the next section for the specification of $R$ ). Moreover, the compositional anchor $x$ for linking the free relative clause to the matrix VP is not said to be identical to $v$, but only equivalent to it. Note as well that the resulting predicate denotation is straightforwardly amenable to a second use of MOD* at the matrix level (this will be spelled out in more detail in the next section). ${ }^{15}$

The analysis of V-HCCs with wie is now straightforward. Since the structure of $\mathrm{V}$-HCCs given in (45b) is analogous to that of ordinary free relatives, their semantics may unfold in the same way; compare (62): wie's base is associated with a predicate of equivalence, introducing the relation sim. While the head-adjacent base position triggers integration via MOD* - that is, the introduction of a free variable $v$ that is linked to the silent $\mathrm{V}$-event via $R$-the $w h$-movement licenses $\lambda$-abstraction over

\footnotetext{
${ }^{15}$ The attentive reader might ask how the given alternative analysis deals with the quantificational variation of free relative clauses that is at the heart of the analyses in both Caponigro (2004) and Hinterwimmer (2013) (who, however, only deals with DP-like free relative clauses). Again, an elaborate discussion is beyond the present paper. I would merely like to point out that PP-like free relative clauses are particularly open to both definite and indefinite readings; in fact, one might argue (partly on a par with Caponigro; see fn. 14) that the interpretation of (51a) and (51b) as definites or indefinites is largely a matter of plausibility. To my intuition, free relative clauses with wie are indeterminate as well: one cannot really tell whether (54) is about Ben's cycling in the way(s) Mia is cycling or in $a$ way Mia is cycling. The free variable account proposed here is compatible with leaving it to co(n)textual knowledge whether $v$ is treated as a unique or a non-unique entity.
} 
sim's second argument $x$. There is only one additional complication: as argued for above, V-HCCs come with a quantificational structure triggered by the conditional antecedent; therefore, one has to decide which part of the VP goes to the restrictor and which part goes to the nuclear scope. I assume that moving wie warrants that the whole silent VP, except for the contribution made by the modifying equivalence relation, is background information; this licenses its accommodation within the restrictor of the modal and yields the copies of $\llbracket \ldots \mathrm{V} \rrbracket$ in the restricting parts. The corresponding events then join the respective antecedent event by sum formation.

$$
\begin{aligned}
\llbracket \text { wie }_{i} & \mathrm{OP}_{\forall} \ldots \mathrm{t}_{i} \mathrm{~V} \text { wenn er betrunken ist } \rrbracket \\
= & \lambda x . \forall w^{\prime}\left[w ^ { \prime } \in \operatorname { B e s t } _ { g } ( w ) \left(\bigcap \left(f ( w ) \cup \left\{\left\{w^{\prime \prime}: \exists e^{\prime \prime} \oplus e^{\prime \prime \prime}\left[e^{\prime \prime} \oplus e^{\prime \prime \prime} \leq w^{\prime \prime} \wedge\right.\right.\right.\right.\right.\right. \\
& \left.\left.\left.\left.\left.\operatorname{drunk}^{\prime}\left(e^{\prime \prime}, \text { Ben }\right) \wedge \llbracket \ldots \mathrm{V} \rrbracket\left(e^{\prime \prime \prime}\right)\right]\right\}\right\}\right)\right) ; \\
& \forall e \oplus e^{\prime}\left[e \oplus e^{\prime} \leq w^{\prime} \wedge \operatorname{drunk}^{\prime}(e, \operatorname{Ben}) \wedge \llbracket \ldots \mathrm{V} \rrbracket\left(e^{\prime}\right) ; \exists s \exists e^{\prime \prime \prime \prime}\left[e \oplus e^{\prime} \leq\right.\right. \\
& \left.\left.\left.s \wedge e^{\prime}=e^{\prime \prime \prime \prime} \wedge \llbracket \ldots \mathrm{V} \rrbracket\left(e^{\prime \prime \prime \prime}\right) \wedge R\left(e^{\prime \prime \prime \prime}, v\right) \wedge \operatorname{sim}^{\prime}(v, x, F)\right]\right]\right]
\end{aligned}
$$

In prose: the $\mathrm{V}-\mathrm{HCC}$ in (45a) denotes-relative to $w, f$, and $g$ - the set of $x$ so that the following holds for all $g$-best worlds $w^{\prime}$ in the set of $f$-accessible worlds that contain an event of Ben's being drunk plus a V-event: all events $e \oplus e^{\prime}$ that are part of $w^{\prime}$ and are an event of Ben's being drunk plus the V-event can be extended to a situation $s$ where $x$ is equivalent to some $v$ that is linked to this very V-event via R.

The resulting logical form has two crucial positive ramifications: it predicts that the underspecified V-event forms a part of the operator's restriction. This is as desired; recall (with a specification of $x$ to a manner) the greatly simplified contrast in (63), repeated from (20) and (21) above:

a. \# $\{w$ : Ben is drunk in $w\} \subseteq\{w$ : Ben is cycling in a manner $x$ in $w\}$

b. $\checkmark\{w$ : Ben is drunk and is cycling in $w\} \subseteq\{w$ : Ben is cycling in a manner $x$ in $w\}$

What is even more important, the logical set-up facilitates an easy account of the various readings of V-HCCs: they simply follow from different assignments to the conversational backgrounds $g$ and $f$.

The extensional reading is repeated in (64):

(64) a. (Ben fährt Rad,) wie wenn er betrunken ist. (Ben cycles) how if he drunk is

b. '(Ben is cycling) as he always does when he is drunk.'

It is characterized by the fact that no alternative worlds are involved. This can be captured by letting $f$ be a totally realistic conversational background, that is, a background that pairs every world with exactly those facts that describe the respective world completely. Accordingly, $\bigcap f(w)=\{w\}$, which renders the actual world $w$ the only accessible one; trivially, then, $w$ is also the $g$-best world. The logical form in (62) thereby boils down to (65), which provides an adequate description of the extensional reading.

$$
\begin{aligned}
& \llbracket \text { wie }_{i} \mathrm{OP} \forall \ldots \mathrm{t}_{i} \mathrm{~V} \text { wenn er betrunken ist } \rrbracket^{w} \\
& =\lambda x . \forall e \oplus e^{\prime}\left[e \oplus e^{\prime} \leq w \wedge \operatorname{drunk}^{\prime}(e, \mathrm{Ben}) \wedge \llbracket \ldots \mathrm{V} \rrbracket\left(e^{\prime}\right) ; \exists s \exists e^{\prime \prime \prime \prime}\left[e \oplus e^{\prime} \leq\right.\right. \\
& \left.\left.\quad s \wedge e^{\prime}=e^{\prime \prime \prime \prime \prime} \wedge \llbracket \ldots \mathrm{V} \rrbracket\left(e^{\prime \prime \prime \prime}\right) \wedge R\left(e^{\prime \prime \prime \prime}, v\right) \wedge \operatorname{sim}^{\prime}(v, x, F)\right]\right]
\end{aligned}
$$


In prose, the V-HCC in (64) denotes-relative to $w$-the set of $x$ so that the following holds for $w$ : all events $e \oplus e^{\prime}$ that are part of $w$ and are an event of Ben's being drunk plus a V-event can be extended to a situation $s$ where $x$ is equivalent to some $v$ that is linked to this very V-event via R. ${ }^{16}$

The generic reading, repeated in (66), involves a relativization to normal worlds with normal entities.

(66) a. (Ben fährt Rad,) wie wenn er betrunken ist. (Ben cycles) how if he drunk is

b. '(Ben is cycling) as he usually does when he is drunk.'

This can be modeled by combining an empty modal base with a stereotypical ordering source. Such a $g_{\text {stereotype }}$ prefers worlds with situations and entities that are as normal as possible from the perspective of the actual world. The corresponding V-HCC then receives the representation in (67).

$$
\begin{array}{rl}
\llbracket \text { wie }_{i} & \mathrm{OP} \forall \ldots \mathrm{t}_{i} \mathrm{~V} \text { wenn er betrunken ist } \rrbracket^{w, g_{\text {stereotype }}} \\
= & \lambda x . \forall w^{\prime}\left[w ^ { \prime } \in \text { Best } _ { g _ { \text { stereotype } } ( w ) } \left(\bigcap \left(\left\{\left\{w^{\prime \prime}: \exists e^{\prime \prime} \oplus e^{\prime \prime \prime}\left[e^{\prime \prime} \oplus e^{\prime \prime \prime} \leq w^{\prime \prime} \wedge\right.\right.\right.\right.\right.\right. \\
& \left.\left.\left.\left.\left.\operatorname{drunk}^{\prime}\left(e^{\prime \prime}, \mathrm{Ben}\right) \wedge \llbracket \ldots \mathrm{V} \rrbracket\left(e^{\prime \prime \prime}\right)\right]\right\}\right\}\right)\right) ; \\
& \forall e \oplus e^{\prime}\left[e \oplus e^{\prime} \leq w^{\prime} \wedge \operatorname{drunk}^{\prime}(e, \operatorname{Ben}) \wedge \llbracket \ldots \mathrm{V} \rrbracket\left(e^{\prime}\right) ; \exists s \exists e^{\prime \prime \prime \prime}\left[e \oplus e^{\prime} \leq\right.\right. \\
& \left.\left.\left.s \wedge e^{\prime}=e^{\prime \prime \prime \prime \prime} \wedge \llbracket \ldots \mathrm{V} \rrbracket\left(e^{\prime \prime \prime \prime}\right) \wedge R\left(e^{\prime \prime \prime \prime}, v\right) \wedge \operatorname{sim}^{\prime}(v, x, F)\right]\right]\right]
\end{array}
$$

In prose, the V-HCC in (66) denotes-relative to $w$ and $g_{\text {stereotype }}$ - the set of $x$ so that the following holds for all worlds $w^{\prime}$ in the set of worlds that contain an event of Ben's being drunk plus a V-event so that $w^{\prime}$ is most normal from the perspective of $w$ : all events $e \oplus e^{\prime}$ that are part of $w^{\prime}$ and are an event of Ben's being drunk plus the $\mathrm{V}$-event can be extended to a situation $s$ where $x$ is equivalent to some $v$ that is linked to this very $\mathrm{V}$-event via $\mathrm{R}$.

In (68), the counterfactual reading is reproduced.

a. (Ben fährt Rad,) wie wenn er betrunken wäre. (Ben cycles) how if he drunk were

b. '(Ben is cycling) as he would cycle if he were drunk.'

As said above, I follow the Stalnaker-Lewis viewpoint that counterfactuals render accessible only those worlds that are as similar as possible to the actual world given that the antecedent is true. Within Kratzer's (1991b) framework, such a reading follows from an empty modal base $f$ and a totally realistic ordering source $g$. For the case at hand, this yields the interpretation in (69). As desired, only worlds are considered that are maximally similar to the actual world while entailing the antecedent plus its accommodated V-event.

\footnotetext{
${ }^{16}$ Note that the rough paraphrase given in $(64 \mathrm{~b})$ presumes that the relevant V-event corresponds to the event description at the explicit matrix level (the same holds for the following exposition of the other readings). Recall, however, that this should not be invariably tied to the semantic composition; it is, therefore, as desired that the representation in (65) does not constrain the relevant V-event directly. I come back to this issue in the following section.
} 


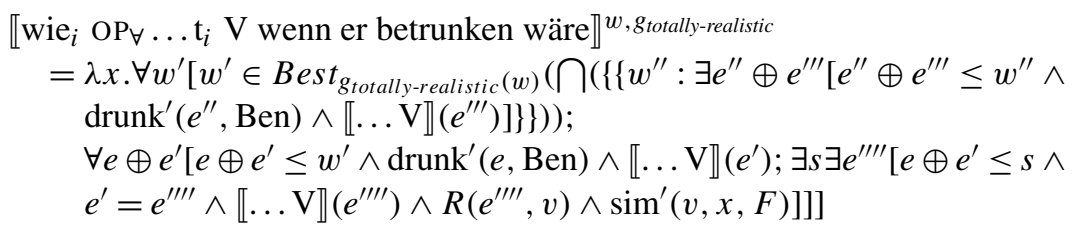

In prose, the V-HCC in (68) denotes - relative to $w$ and $g_{\text {totally-realistic - the set of }}$ $x$ so that the following holds for all worlds $w^{\prime}$ in the set of worlds that contain an event of Ben's being drunk plus a V-event so that $w^{\prime}$ is most similar to $w$ : all events $e \oplus e^{\prime}$ that are part of $w^{\prime}$ and are an event of Ben's being drunk plus the V-event can be extended to a situation $s$ where $x$ is equivalent to some $v$ that is linked to this very V-event via R.

Notably, the fact that the counterfactual reading of V-HCCs depends on verb forms in the counterfactual subjunctive follows from an independent assumption: the explicit antecedent with a verb form in the counterfactual subjunctive correlates systematically with a silent operator that corresponds to would and, thus, triggers the conversational backgrounds characteristic of the counterfactual reading.

The epistemic reading is repeated in (70).

a. (Ben fährt Rad,) wie wenn er betrunken ist.

(Ben cycles) how if he drunk is

b. '(Ben is cycling) as, in my view, he must cycle if he is drunk.'

The crucial dependence on the speaker's knowledge and belief follows from assuming an epistemic modal base and a doxastic ordering source. This is exemplified in (71).

$$
\begin{aligned}
& \llbracket \text { wie }_{i} \mathrm{OP}_{\forall} \ldots \mathrm{t}_{i} \mathrm{~V} \text { wenn er betrunken ist } \rrbracket^{w, f_{\text {epistemic }}, g_{\text {doxastic }}} \\
& =\lambda x . \forall w^{\prime}\left[w ^ { \prime } \in \text { Best } _ { g _ { \text { doxastic } } ( w ) } \left(\bigcap \left(f _ { \text { epistemic } } ( w ) \cup \left\{\left\{w^{\prime \prime}: \exists e^{\prime \prime} \oplus\right.\right.\right.\right.\right. \\
& \left.\left.\left.\left.\quad e^{\prime \prime \prime}\left[e^{\prime \prime} \oplus e^{\prime \prime \prime} \leq w^{\prime \prime} \wedge \operatorname{drunk}^{\prime}\left(e^{\prime \prime}, \mathrm{Ben}\right) \wedge \llbracket \ldots \mathrm{V} \rrbracket\left(e^{\prime \prime \prime}\right)\right]\right\}\right\}\right)\right) ; \\
& \quad \forall e \oplus e^{\prime}\left[e \oplus e^{\prime} \leq w^{\prime} \wedge \operatorname{drunk}^{\prime}(e, \mathrm{Ben}) \wedge \llbracket \ldots \mathrm{V} \rrbracket\left(e^{\prime}\right) ; \exists s \exists e^{\prime \prime \prime \prime}\left[e \oplus e^{\prime} \leq s \wedge e^{\prime}\right.\right. \\
& \left.\left.\left.\quad=e^{\prime \prime \prime \prime} \wedge \llbracket \ldots \mathrm{V} \rrbracket\left(e^{\prime \prime \prime \prime}\right) \wedge R\left(e^{\prime \prime \prime \prime}, v\right) \wedge \operatorname{sim}^{\prime}(v, x, F)\right]\right]\right]
\end{aligned}
$$

In prose, the V-HCC in (70) denotes-relative to $w, f_{\text {epistemic }}$, and $g_{\text {doxastic }}$ - the set of $x$ so that the following holds for all worlds $w^{\prime}$ so that $w^{\prime}$ is closest to the beliefs of the speaker in $w$, given that $w^{\prime}$ is in the set of worlds that contain an event of Ben's being drunk plus a V-event and are compatible with the knowledge of the speaker in $w$ : all events $e \oplus e^{\prime}$ that are part of $w^{\prime}$ and are an event of Ben's being drunk plus the $\mathrm{V}$-event can be extended to a situation $s$ where $x$ is equivalent to some $v$ that is linked to this very $\mathrm{V}$-event via $\mathrm{R}$.

This section has shown that the internal semantics of V-HCCs can be derived in a fairly regular way. The derivation takes seriously the equivalence relation contributed by the wh-pronoun wie and the effects that result from moving it out of a silent consequent. Furthermore, the explicit conditional antecedent licenses a universal operator that renders V-HCCs sensitive to conversational backgrounds and thereby accounts for their different readings in a systematic fashion. For ease of presentation, I sim- 
plify this interim result; see the representation in (72b) for (72a). Essentially, $E_{\text {hypo }}$ abbreviates the contribution made by the conditional structure (including the explicit antecedent) and its implicit modalization. So, (72b) says in prose that the V-HCC denotes a set of $x$ so that $x$ is equivalent to all variables $V$ that are linked to hypothetical events $E_{\text {hypo. }}{ }^{17}$
a. (Ben fährt Rad) wie ${ }_{i}\left[V P \ldots t_{i} \mathrm{~V}\right.$ wenn er betrunken ist].
b. $\lambda x \exists E_{\text {hypo }}\left[R\left(E_{\text {hypo }}, V\right) \wedge \operatorname{sim}^{\prime}(V, x, F)\right]$

As desired, the representation is fully analogous to the one for ordinary free relative clauses except for not yet specifying the relevant events $E_{\text {hypo }}$; compare (72) to (73a) and its representation in (73b) (repeated from (60) above).
a. (Ben fährt Rad) wie ${ }_{i}$ [VP Mia $t_{i}$ Rad fährt].
b. $\lambda x \exists e\left[\operatorname{cycle}^{\prime}(e) \wedge \operatorname{ag}^{\prime}(e\right.$, Mia $\left.) \wedge R(e, v) \wedge \operatorname{sim}^{\prime}(v, x, F)\right]$

The next derivational step comprises the integration of V-HCCs within their matrix hosts.

\subsection{The external semantics of V-HCCs: Linking V-HCCs to the matrix clause}

\subsubsection{On the syntactic backbone for compositionally integrating V-HCCs}

While previous research on HCCs widely agrees upon the fact that V-HCCs are integrated within their matrix hosts (see the contrast between S-HCCs and V-HCCs discussed in Sect. 3 above), their exact integration site is not determined in detail. From a compositional perspective, however, such details are important. Crucially, manner and predicative readings of modifiers depend on a free variable that mediates between the modifier and the verbal event; according to MOD*, such a mediation is licensed only if the modifier targets the verbal head. Therefore, V-HCCs should not relate to some higher level of the (extended) verbal projection of the matrix clause, but to the verbal head itself, as in (75) for (74).

(74) dass Ben einen Bentley parkt wie wenn er betrunken wäre that Ben a Bentley parks how if he drunk were 'that Ben is parking a Bentley as if he were drunk'

\footnotetext{
${ }^{17}$ The use of the capital letter $E$ is meant to be reminiscent of the fact that we are dealing here with (infinitely) many events. This fact is due to the complex quantificational structure that is left out in the abbreviation. (For instance, the epistemic reading represented by (71) renders those hypothetical events relevant that exist in epistemically and doxastically accessible worlds; of course, there are (infinitely) many of such worlds.) Correspondingly, each of these events is linked to a variable $v$; that is, we are also dealing with (infinitely) many $v$, as indicated by the use of the capital letter $V$. To be sure, I do not conceive of $R$ to hold between sets, or, of 'sim' ' to hold between a particular and a set; in fact, one has to adequately distribute these relations over the particulars that form the (infinite) sets $E_{\text {hypo }}$ and $V$.
} 
(75)

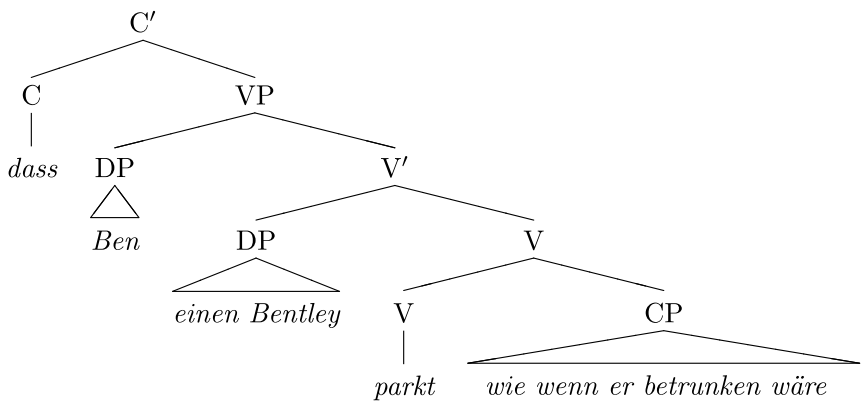

In fact, there is good independent evidence for such a configuration (see, for instance, Frey and Pittner 1998, Maienborn 2001, or Frey 2003 for a general introduction to base positions of adverbials in German and to syntactic tests to identify them). For one, both variable binding, as in (76), and principle-C effects, as in (77), indicate that V-HCCs project below the object. The quantifiers kein Auto ('no car') and jede Frau ('every woman') can bind a variable in V-HCCs, which requires that they c-command the respective V-HCC. In turn, independently referring terms such as sein Auto ('his car') and Mia are not allowed to be c-commanded by co-referential expressions according to binding principle $\mathrm{C}$.

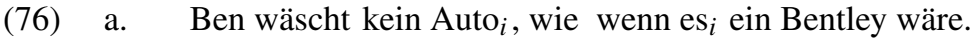

Ben washes no car how if it a Bentley were

'Ben doesn't wash any car $_{i}$ in a way as if it $i_{i}$ were a Bentley.'

b. Ben schaut jede $\mathrm{Frau}_{i}$ an, wie wenn er in $\mathrm{sie}_{i}$ verliebt wäre.

Ben looks at every woman how if he with her in love were

'Ben looks at every $\operatorname{woman}_{i}$ in a way as if he were in love with her ${ }_{i}$.'

(77) a. Ben wäscht $\left\{\right.$ sein Auto $\left._{i} / * \mathrm{es}_{j}\right\}$, wie wenn $\left\{\mathrm{es}_{i} / \operatorname{sein} \mathrm{Auto}_{j}\right\}$ ein

Ben washes $\{$ his car / it $\}$ how if $\{$ it / his car $\}$ a

Bentley wäre.

Bentley were

'Ben washes $\left\{\right.$ his $\left.\operatorname{car}_{i} / *_{\mathrm{it}}\right\}$ in a way as if $\left\{\mathrm{it}_{i} / \mathrm{his} \operatorname{car}_{j}\right\}$ were a Bentley.'

b. Ben schaut $\left\{\mathrm{Mia}_{i} / * \operatorname{sie}_{j}\right\}$ an, wie wenn er in $\left\{\mathrm{sie}_{i} / \mathrm{Mia}_{j}\right\}$ verliebt Ben looks at $\{\mathrm{Mia} / \mathrm{her}\} \quad$ as if he in $\{$ her / Mia $\}$ in love wäre.

were

'Ben looks at $\left\{\mathrm{Mia}_{i} /{ }^{*} \operatorname{her}_{j}\right\}$ as if he were in love with $\left\{\right.$ her $\left._{i} / \mathrm{Mia}_{j}\right\}$.'

Moreover, if V-HCCs are accompanied by a correlative pronoun in the middlefield, this pronoun must be closer to the verb than the object, as in (78).

(78) Paula hat (*so) einen Bentley (so) geparkt, wie wenn sie beTRUNken

Paula has (so) a Bentley (so) parked how if she drunk

wäre.

were

'Paula has parked a Bentley in a way as if she were drunk.' 
Examples with (remnant) topicalization such as (79) suggest as well that V-HCCs are adjacent to the verbal head. Accordingly, (79a) is deviant because the topicalization yields an unbound trace whereas $(79 \mathrm{~b})$ is fine because it does not involve a binding violation. $^{18}$

a. ?? [Gefragt $\mathrm{t}_{j}$, ob Ufos gelandet seien, $]_{i}$ hat Peter, [wie wenn er [asked $\mathrm{t}_{j}$ whether UFOs landed be] $]_{i}$ has Peter [how if he in PAnik wäre $]_{j} \mathrm{t}_{i}$. in panic were $]_{j} \mathrm{t}_{i}$ 'Peter asked as if he were terrified whether UFOs have landed.'

b. [Gefragt, wie wenn er in Panik wäre, $]_{i}$ hat Peter $t_{i}$, ob UFOs [asked how if he in panic were $]_{i}$ has Peter $t_{i}$ whether UFOs gelandet seien.

landed be

In evaluating these sentences, one has to keep in mind that the relevant HCCs should be manner adverbials here; this correlates with the whole sentences having only one focus-background structure and, thus, only one main accent. If, by contrast, the HCCs were treated as separate non-integrated S-HCCs, the complex sentences would receive two main accents and become grammatical; of course, no binding violation may arise here. Compare the S-HCC variant of (79a) in (80) for illustration: it does not contribute a manner description, but roughly says that asking about UFOs is reasonable for Peter in situations where he is panicking.

(80) [Gefragt, ob UFOs gelandet seien, $]_{i}$ hat Peter $t_{i}$, [wie wenn er in PAnik wäre].

Finally, with both an object clause and a V-HCC in the postfield, the linearization 'V-HCC > object' is preferred over 'object $>$ V-HCC'; see (81a) as opposed to (81b). (Again, the integrated manner interpretation of the V-HCC must be assumed; as a S-HCC, (81b) would be fine.) The linearization preference is also reflected by the fact that event-elaborating indem-clauses-which semantically scope at the level above objects (see Bücking 2014 for their semantics)—must follow V-HCCs; see the contrast in (82). (The contrast emerges only if the subordinate clauses are not read as parentheticals, but rather integrated in just one focus-background structure for the whole complex sentences.)

a. Paul hat Maria gefragt, wie wenn er in Panik wäre, ob UFOs Paul has Maria asked how if he in panic were whether UFOs gelandet seien.

landed be

'Paul asked Maria as if he were terrified whether UFOs have landed.'

b. ?? Paul hat Maria gefragt, ob Ufos gelandet seien, wie wenn er Paul has Maria asked whether UFOs landed be how if he in PAnik wäre.

in panic were

'Paul asked Maria whether UFOs have landed as if he were terrified.'

\footnotetext{
${ }^{18}$ For Ufo ('UFO'), capitalization of the first syllable is not distinctive for marking a main accent. Therefore, if $U f o$ is assigned the main accent, all three letters are capitalized.
} 
(82) a. Paul begleitet die Diskussion, wie wenn sie ihm egal

Paul accompanies the discussion as if it to him of no concern wäre, indem er demonstrativ aus dem FENSter schaut.

were in that he pointedly out of the window looks

'Paul is accompanying the discussion as if he didn't care by pointedly looking out of the window.'

b. * Paul begleitet die Diskussion, indem er demonstrativ aus dem Paul accompanies the discussion in that he pointedly out of the Fenster schaut, wie wenn sie ihm eGAL wäre. window looks as if it to him of no concern were 'Paul is accompanying the discussion by pointedly looking out of the window as if he didn't care.'

In sum, the submitted evidence supports the structure in (75), where the compositional integration of the V-HCC precedes the one for objects, subjects, or other higher-level adverbials; see below for the corresponding derivation.

Let me conclude this subsection by relating the given result to the more general question of how to account for (adverbial) adjuncts at the right periphery of a head. The corresponding debates have mainly focused on adverbials that follow the English VP; see, for instance, Pesetsky (1995), Ernst (2002), Frey (2003), Haider (2002, 2004), and Cinque (2004). Further domains touched upon are the postfield in German sentences and adnominal modifiers; see, again, Haider's work and Bücking (2012). From a descriptive point of view, there is wide agreement on the following rather puzzling pattern: on the one hand, subdomains precede superdomains, suggesting some kind of upward adjunction; on the other hand, binding facts favor an analysis with the right-hand constituents being deeply embedded. The following examples from Haider (2002) serve as an illustration:

a. She has worked [on her hobby] [with great care] [in the garden] [today].

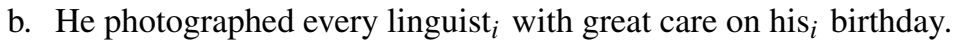

(see Haider 2002: ex. (41a) and (42a))

In order to solve this major challenge, Haider (2004) argues for treating (certain) right-peripheral adverbials as base-generated extraposed constituents. ${ }^{19}$ The relevant extraposition domain is a strictly right-branching structure licensed by a purely structural head which is not able to identify positions lexically; the guiding intuition here is that a head's lexical projection, namely its argument structure, is already closed at the right edge. While binding relations are sensitive to the structural embedding, the lack of properly identifying right-peripheral adverbials precludes their usual compositional integration and thereby triggers an incremental interpretation where subdomains must precede superdomains. Example (84) provides an illustration with ex-

${ }^{19}$ I will follow his idea here; see Rosengren (2003) for a similar account and Bücking (2012) for a transfer of Haider's approach to adnominal modifiers in terms of formal semantics. Opposing views are defended by Ernst (1994), Pesetsky (1995), and Cinque (2004). 
traposed elements in bold; the lack of an index on $t$ symbolizes the head's purely structural role. Notably, for German, the extraposition domain is usually considered readily identifiable because it follows the base position of verbs at the right-hand side (but see below); in (84b), this position is marked by the verbal particle hinunter.

a. She $\left[{ }_{V P}\right.$ handed $_{i}\left[\right.$ him $\left[V_{V^{0}} \mathrm{t}_{i}\right.$ down] [something [ $\mathrm{t}_{i}$ [in the hall [t before midnight]] ]]]].

b. Sie reichte ${ }_{i}$ ihm etwas hinunter $t_{i}$ [in der Halle [t vor she handed ${ }_{i}$ him something down $\mathrm{t}_{i}$ [in the hall $[\mathrm{t}$ before

Mitternacht]].

midnight]].

(see Haider 2004: ex. (38a) and (38b))

How do V-HCCs fit into this picture? As shown above, they behave as expected: hierarchically, they are embedded; linearly, they immediately follow the verbal head, which is in line with the preferred linearization 'subdomain $>$ superdomain.' Crucially, however, since this is as one would hope from an ordinary compositional perspective, V-HCCs do not pose the particular challenge higher-level adverbials are subject to. In terms of Haider's proposal, V-HCCs should thus not be part of the incrementally interpreted right periphery, but a component of the regular structural integration. Although V-HCCs are projected to the right-hand side of the verb, I conjecture that V-HCCs are not constituents of the extraposed postfield that is sensitive to incremental interpretation. This conjecture can be backed up as follows: for one, if V-HCCs contribute to the verbal complex itself, the notion of a postfield constituent is not applicable to V-HCCs to begin with. Furthermore, non-clausal manner adverbials and other V-related cases such as event-internal locatives (see Maienborn 2001, 2003b and Bücking 2012) are not allowed to the right of the verb; see, for instance, (85):

\footnotetext{
* Er hat protestiert lautstark.

he has protested vociferously

'He protested vociferously.'
}

(see Haider 2004: ex. (42d))

In fact, according to Haider, this observation substantiates the existence of an incremental domain, and indicates that V-related manner adverbials are not part of it. Then, V-HCCs (which are not discussed by Haider) are an exception that proves the rule: for principled reasons, adverbial sentences cannot be part of the middlefield proper (see, for instance, Reich and Reis 2013); this holds true for V-HCCs as well; see Bücking (2015) and the examples in (86). ${ }^{20}$

$$
\begin{aligned}
& \text { a. * Mia hat, wie wenn sie WÜtend wäre, geschimpft. } \\
& \text { Mia has how if she angry were cursed } \\
& \text { 'Mia cursed as if she were angry.' }
\end{aligned}
$$

\footnotetext{
${ }^{20}$ The given examples get better if the V-HCCs and the host sentences receive separate focus-background structures, that is, separate main accents. The same holds for other types of adverbial clauses that are inserted to the left of the verbal base position. However, Reich and Reis (2013) suggest that such separate clauses do not occupy positions in the middlefield proper, but parenthetic slots; accordingly, they do not participate in the regular composition of the verbal left-hand projection.
} 
b. * Hanno hat die Gans, wie wenn er MITleid mit ihr hätte, Hanno has the goose how if he pity with it had angeschaut.

looked at

'Hanno looked at the goose as if he felt sorry for it.'

(see Bücking 2015: ex. (36a, b))

Therefore, V-HCCs must follow the verbal head, but they do so as early as possible: they still project within the ordinary structural realm of the verb. ${ }^{21}$

\subsubsection{The compositional derivation of the semantic form and its conceptual specification}

A structural input as in (75) above, see the sketch in (87), and the meaning components in (88) (where (88c) is the (abbreviated) meaning of the V-HCC motivated in Sect. 4.1) yield, based on MOD* as repeated in (89), the stepwise derivation in (90):

(87) dass [ ${ }_{V P}$ Ben $\left[{ }_{V}\left[{ }_{V}\right.\right.$ Rad fährt $][C P$ wie wenn er betrunken ist $\left.\left.]\right]\right]$.

(88) a. $\llbracket \mathrm{Ben} \rrbracket=$ Ben

b. $\llbracket \operatorname{Rad}$ fährt $\rrbracket=\lambda y^{\prime} \lambda e^{\prime} \cdot \operatorname{cycle}^{\prime}\left(e^{\prime}\right) \wedge \operatorname{ag}^{\prime}\left(e^{\prime}, y^{\prime}\right)$

c. «wie wenn er betrunken ist》

$$
=\lambda x^{\prime} \exists E_{\text {hypo }}\left[R\left(E_{\text {hypo }}, V^{\prime}\right) \wedge \operatorname{sim}^{\prime}\left(V^{\prime}, x^{\prime}, F\right)\right]
$$

(89) $\quad$ a. $\mathrm{MOD}^{*}=\lambda Q \lambda P \ldots \lambda x . P(\ldots)(x) \wedge R(x, v) \wedge Q(v)$

b. Condition on the application of MOD*:

If MOD* is applied in a structural environment of categorial type $\mathrm{X}$, then

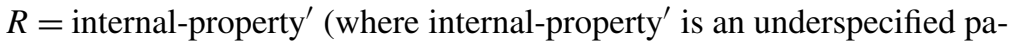
rameter for a manner, circumstance, or result function), otherwise (that is, in an XP-environment) $R=$ identity' $^{\prime}$.

(90) a. MOD*(【wie wenn er betrunken ist $\rrbracket)$

$$
\begin{aligned}
= & {\left[\lambda Q \lambda P \ldots \lambda x . P(\ldots)(x) \wedge R^{\prime}(x, v) \wedge Q(v)\right] } \\
& \left(\lambda x^{\prime} \exists E_{\text {hypo }}\left[R\left(E_{\text {hypo }}, V^{\prime}\right) \wedge \operatorname{sim}^{\prime}\left(V^{\prime}, x^{\prime}, F\right)\right]\right) \\
= & \lambda P \ldots \lambda x . P(\ldots)(x) \wedge R^{\prime}(x, v) \wedge \exists E_{\text {hypo }}\left[R\left(E_{\text {hypo }}, V^{\prime}\right)\right. \\
& \left.\wedge \operatorname{sim}^{\prime}\left(V^{\prime}, v, F\right)\right]
\end{aligned}
$$

b. 【Rad fahren wie wenn er betrunken ist $\rrbracket$

$=[\mathrm{MOD} *(\llbracket$ wie wenn er betrunken ist $\rrbracket)](\llbracket \operatorname{Rad}$ fahren $\rrbracket)$

$=\left[\lambda P \ldots \lambda x . P(\ldots)(x) \wedge R^{\prime}(x, v) \wedge \exists E_{\text {hypo }}\left[R\left(E_{\text {hypo }}, V^{\prime}\right)\right.\right.$

$\left.\left.\wedge \operatorname{sim}^{\prime}\left(V^{\prime}, v, F\right)\right]\right]\left(\lambda y^{\prime} \lambda e^{\prime} . \operatorname{cycle}^{\prime}\left(e^{\prime}\right) \wedge \operatorname{ag}^{\prime}\left(e^{\prime}, y^{\prime}\right)\right)$

$=\left[\lambda P \lambda y \lambda x . P(y)(x) \wedge R^{\prime}(x, v) \wedge \exists E_{\text {hypo }}\left[R\left(E_{\text {hypo }}, V^{\prime}\right)\right.\right.$

$\left.\left.\wedge \operatorname{sim}^{\prime}\left(V^{\prime}, v, F\right)\right]\right]\left(\lambda y^{\prime} \lambda e^{\prime} . \operatorname{cycle}^{\prime}\left(e^{\prime}\right) \wedge \operatorname{ag}^{\prime}\left(e^{\prime}, y^{\prime}\right)\right)$

$=\lambda y \lambda x \cdot \operatorname{cycle}^{\prime}(x) \wedge \operatorname{ag}^{\prime}(x, y) \wedge R^{\prime}(x, v) \wedge \exists E_{\text {hypo }}\left[R\left(E_{\text {hypo }}, V^{\prime}\right)\right.$

$\left.\wedge \operatorname{sim}^{\prime}\left(V^{\prime}, v, F\right)\right]$

\footnotetext{
${ }^{21}$ Bücking (2012) argues that right-peripheral modifiers within complex noun phrases also show an 'invisible' boundary between the structural and the incremental domain.
} 
c. «Ben Rad fährt wie wenn er betrunken ist

$=\left[\left[\mathrm{MOD}^{*}(\llbracket\right.\right.$ wie wenn er betrunken ist $\left.\rrbracket)\right](\llbracket \operatorname{Rad}$ fahren $\left.\rrbracket)\right](\llbracket \mathrm{Ben} \rrbracket)$

$=\lambda x \cdot \operatorname{cycle}^{\prime}(x) \wedge \operatorname{ag}^{\prime}(x$, Ben $) \wedge R^{\prime}(x, v) \wedge \exists E_{\text {hypo }}\left[R\left(E_{\text {hypo }}, V^{\prime}\right)\right.$ $\left.\wedge \operatorname{sim}^{\prime}\left(V^{\prime}, v, F\right)\right]$

With existentially closing the event argument and substituting it with the more transparent variable $e$, the (simplified) truth conditions for the full sentence are as follows:

$$
\begin{aligned}
& \exists e\left[\operatorname { c y c l e } ^ { \prime } ( e ) \wedge \operatorname { a g } ^ { \prime } ( e , \text { Ben } ) \wedge R ^ { \prime } ( e , v ) \wedge \exists E _ { \text { hypo } } \left[R\left(E_{\text {hypo }}, V^{\prime}\right)\right.\right. \\
& \left.\left.\quad \wedge \operatorname{sim}^{\prime}\left(V^{\prime}, v, F\right)\right]\right]
\end{aligned}
$$

This says that there is an event of Ben's cycling related to some $v$ that is equivalent to those $V^{\prime}$ related to hypothetical events $E_{\text {hypo }}$.

This resulting semantic form is underspecified and, thus, amenable to a conceptually plausible specification. According to MOD*, one option is to resolve $R$ and $R^{\prime}$ to a manner function. For concreteness, let us assume that both are specified to 'manner' form ', that is, a function from events to manners of form; see (92). (I will explain below why both $R s$ should be specified to the same kind of function.)

$$
\begin{aligned}
& \exists e\left[\operatorname{cycle}^{\prime}(e) \wedge \operatorname{ag}^{\prime}(e, \text { Ben }) \wedge \operatorname{manner}_{\text {form }}^{\prime}(e, v)\right. \\
& \left.\wedge \exists E_{\text {hypo }}\left[\operatorname{manner}_{\text {form }}^{\prime}\left(E_{\text {hypo }}, V^{\prime}\right) \wedge \operatorname{sim}^{\prime}\left(V^{\prime}, v, F\right)\right]\right]
\end{aligned}
$$

As a result, (92) says that the form manner of Ben's cycling is equivalent to the form manners of the hypothetical events introduced within the V-HCC; plausible candidates for $E_{\text {hypo }}$ are events of Ben's cycling in situations where he is drunk.

In order to flesh out the relevant notion of 'sim', I transfer the analysis of similarity demonstratives in Umbach and Gust (2014) sketched above to the given adverbial case. Accordingly, the manner function can be said to come along with a generalized measure function as in (93), which maps individuals from the universe of form manners to values of an appropriate conceptual attribute space.

$$
\mu_{\text {FORM-MANNER }}: U_{\text {FORM-MANNER }} \rightarrow v \in\{\text { IN WIGGLY LINES, STRAIGHT }, \ldots\}
$$

Notably, since the input in (92) renders the relevant form manners dependent on Ben's cycling (compare the relation between $e$ and $v$ ), the set of potential manners and attribute values is severely constrained, namely, candidates must be compatible with being predicated of cycling events. Moreover, it seems to be obvious that the target domain of form manners is based on a nominal scale, that is, corresponds to a set of unordered elements.

With nominal scales, every value in an attribute space $F$ can be associated with a corresponding basic classifying function $p^{*}$; for the case at hand, this gives us the set of classifying functions $C\left(F_{\mathrm{FORM}-\mathrm{MANNER}}\right)$ in $(94)$. Given the definition for similarity proposed in Umbach and Gust (2014: ex. (37)), and repeated in (95), the form manners $v$ and $V^{\prime}$ in (92) are then similar iff the equivalence relations in (96) hold.

$$
\begin{aligned}
& C\left(F_{\text {FORM-MANNER }}\right)=\{\text { in wiggly lines* } \\
& \operatorname{sim}^{\prime}(x, y, F) \text { iff } \forall p^{*} \in C(F): p^{*}\left(\mu_{F}(x)\right)=p^{*}\left(\mu_{F}(y)\right)
\end{aligned}
$$


(96)
a. in wiggly lines* $\left(\mu_{\text {FORM-MANNER }}(v)\right)$
$=$ in wiggly lines ${ }^{*}\left(\mu_{\text {FORM-MANNER }}\left(V^{\prime}\right)\right)$
b. straight $^{*}\left(\mu_{\text {FORM-MANNER }}(v)\right)=$ straight $^{*}\left(\mu_{\text {FORM-MANNER }}\left(V^{\prime}\right)\right)$
c. $\ldots$

In other words, the manner of the cycling $e$, that is $v$, and the manners of the hypothetical events $E_{\text {hypo }}$, that is $V^{\prime}$, are equivalent in the sense that, regarding their form, they yield uniform mappings: they are either all mapped to IN WIGGLY LINES or all not mapped to IN WIGGLY LINES; they are either all mapped to STRAIGHT or all not mapped to STRAIGHT; etc. The same kind of reasoning could be used, for instance, for speed manners and their corresponding measure function $\mu_{\text {SPEED-MANNER }}$.

The given analysis has the following three merits. First, the manner of the explicit matrix event is not said to be referentially identical to those of the embedded hypothetical events; all manners are merely equivalent with regard to their conceptually determined properties. This is as desired, given the ontological facts discussed in Sect. 2.1.

Second, the analysis does not grammatically determine that V-HCCs receive a manner interpretation. According to $\mathrm{MOD}^{*}, R$ and $R^{\prime}$ can also be instantiated by alternative functions for internal properties such as circumstance ${ }^{\prime}$ or result ${ }^{\prime}$. This is exactly the case with predicative readings. For instance, with $R$ and $R^{\prime}$ as result form $^{\prime}$, (97) receives the conceptual structure in (98a); if the hypothetical events are specified as dressing events and Ben's resulting clothing is specified as the most plausible bearer of each resulting particularized property, (98a) can be refined to (98b).

(97) Ben kleidet sich, wie wenn er in die Oper ginge (nämlich elegant).

Ben dresses how if he in the opera went (namely elegant)

'Ben is dressing as if he went to the opera (namely, elegant).'

$$
\text { a. } \begin{aligned}
\exists e & {\left[\operatorname{dress}^{\prime}(e) \wedge \operatorname{ag}^{\prime}(e, \text { Ben }) \wedge \operatorname{result}_{\text {form }}(e, v)\right.} \\
& \left.\wedge \exists E_{\text {hypo }}\left[\operatorname{result}_{\text {form }}^{\prime}\left(E_{\text {hypo }}, V^{\prime}\right) \wedge \operatorname{sim}^{\prime}\left(V^{\prime}, v, F\right)\right]\right] \\
\text { b. } \exists e & {\left[\operatorname{dress}^{\prime}(e) \wedge \operatorname{ag}^{\prime}(e, \operatorname{Ben}) \wedge \operatorname{result}_{\text {form }}(e, v)\right.} \\
& \wedge \text { bearer }\left(v, \iota c\left[\operatorname{clothing-of~}^{\prime}\left(c, \operatorname{Ben}^{\prime} \wedge \operatorname{result}^{\prime}(e, c)\right]\right)\right. \\
& \wedge \exists E_{\text {hypo }}\left[\operatorname{dress}^{\prime}\left(E_{\text {hypo }}\right) \wedge \operatorname{ag}^{\prime}\left(E_{\text {hypo }}, \operatorname{Ben}\right) \wedge \operatorname{result}_{\text {form }}{ }^{\prime}\left(E_{\text {hypo }}, V^{\prime}\right)\right. \\
& \wedge \text { bearer }\left(V^{\prime}, \iota C^{\prime}\left[\operatorname{clothing-of}^{\prime}\left(C^{\prime}, \text { Ben }\right) \wedge \operatorname{result}\left(E_{\text {hypo }}, C^{\prime}\right)\right]\right) \\
& \left.\left.\wedge \operatorname{sim}^{\prime}\left(V^{\prime}, v, F\right)\right]\right]
\end{aligned}
$$

Accordingly, the form of Ben's clothing, as it results from his actual dressing, is said to be equivalent in some relevant way to the forms of Ben's clothing, as they result from the hypothetical events. A measure function for clothing forms would map both actual form and hypothetical forms to the same value, for instance, ELEGANT. Note as well that ordinary free relative clauses work analogously; compare (99a) with the conceptual structure in (99b). Such free relatives are straightforward because the embedded event is explicitly given.

a. Ben kleidet sich, wie Maria sich kleidet (nämlich elegant). Ben dresses how Maria dresses (namely elegant) 'Ben is dressing as Maria is dressing (namely, elegant).' 


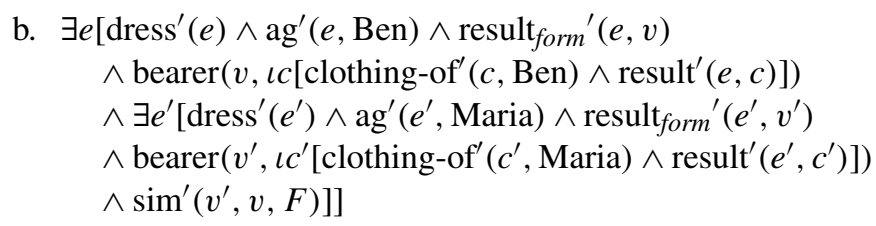

Despite the considerable freedom in determining the relevant entities for comparison, the analysis of V-HCCs and their free relative cognates does not render the instantiation random. The proposed equivalence relation presupposes that the entities said to be equivalent belong to the same supersort; this rules out equivalence between different types of manners and also between manners and results, as is stated in the presupposition failures in (100).
a. \# $\operatorname{sim}\left(v, v^{\prime}, F\right)$, if $v$ and $v^{\prime}$ are of different types of MANNER.
b. \# $\operatorname{sim}\left(v, v^{\prime}, F\right)$, if $v$ is of type MANNER and $v^{\prime}$ of type RESULt.

Recall that for specifying the interpretation of (91) to the manner reading in (92) above, both $R$ and $R^{\prime}$ were specified to a function for manners of form. The presupposition failure in (100a) now explains on principled grounds why the relation variable at the matrix level and the one related to the hypothetical events must be specified to the same kind of manner function. Moreover, the failure in (100b) smoothly explains why one cannot cross predicative and manner readings; see (101) (= (17) above).

(101) Ben kleidet sich, wie Bella sich kleidet, nämlich elegant.

Ben dresses how Bella dresses namely elegant

'Ben dresses as Bella dresses, namely, elegant(ly).'

a. $\checkmark$ 'Ben and Bella dress in an elegant way.', 'Ben and Bella wear elegant clothes.'

b. \# 'Ben dresses in an elegant way and Bella wears elegant clothes.'

However, the presuppositions do not rule out that manners are equivalent across different types of events as long as they are of the same kind. With regard to free relatives, (102) exemplifies this situation for speed manners: in (102a), the participants of the riding events vary; in (102b), even the basic verbal event descriptions are distinct. V-HCCs behave analogously; recall (103) (= (19) above): here, $E_{\text {hypo }}$ is not specified along the lines of the matrix event. The licensing factor, again, is that both events, despite their being distinct, can be associated with the same kind of manner description.

(102) a. Hanno fährt Roller, wie Maria Roller fährt, nämlich rasant. Hanno rides scooter how Maria scooter rides namely very fast 'Hanno rides a scooter as Maria rides a scooter, namely very fast.'

b. Hanno spricht, wie Maria arbeitet, nämlich sehr langsam. Hanno speaks how Maria works namely very slowly 'Hanno speaks as Maria works, namely very slowly.' 
(103) a. Ben fährt Rad, wie wenn ein Mannequin Rad fährt. Ben cycles how if a mannequin cycles

$\neq$ 'Ben is cycling as he cycles when a mannequin cycles.'

$\approx$ 'Ben is cycling as a mannequin cycles when it cycles.'

b. Ben hustet, wie wenn ein Hofhund bellt.

Ben coughs how if a yard dog barks

$\neq$ 'Ben is coughing as he coughs when a yard dog barks.'

$\approx$ 'Ben is coughing. The coughing sounds as it sounds when a yard dog barks.'

Third, the proposed equivalence-based analysis of V-HCCs is compositionally attractive. For one, the regular integration of the inner conditional as discussed in Sect. 4.1 is not disturbed in any way; in fact, the given explicit antecedent and its modalized integration forms a crucial factor in determining the relevant entities of comparison and the particular attribute values to be assigned. For (87), world knowledge tells us that drunkenness may impair the form of driving or cycling; most plausibly, then, the speaker intends to say that Ben is cycling in wiggly lines, perhaps even suggesting (under an epistemic reading) that the reason for this is that he is fact drunk. Moreover, the compositional integration of V-HCCs via MOD* as explicated in (89) makes - without any additional machinery - the correct prediction that the equivalence relation does not hold between events directly, but between eventinternal particularized properties. In turn, the behavior of V-HCCs and free relatives lends support to analyses of manner adverbials in terms of separate ontological entities; see Piñón (2008) and Schäfer (2013). In particular, it is not easily reconcilable with a perspective where $\mathrm{V}$-adjacent adverbials merely contribute to event kinds; see the discussion in Anderson and Morzycki (2015) and Maienborn et al. (2016). Most notably, the data in (102) and (103) show that V-HCCs and free relatives may involve fully different event descriptions. ${ }^{22}$

In the next section, I will discuss how the proposal may be systematically adapted to the sentential counterpart of V-HCCs; this provides one further indirect argument in favor of the given approach.

${ }^{22}$ Furthermore, there are independent reasons for assuming an ontological differentiation. For instance, anaphoric expressions for verbal event descriptions that include manner adverbials suggest that manner adverbials do not yield types of events, but types of manners; see (iia) as opposed to (iib) for (i).

(i) Paul tanzt elegant.

Paul dances elegantly.

(ii) a. \# \{Ein Tanz solcher Art / So ein Tanz $\}$ ist beeindruckend.

\{a dance of such a kind / such a dance $\}$ is impressive

'Such a kind of dance is impressive.'

b. $\checkmark$ Ein Tanzen auf so(lch) eine Art ist beeindruckend.

a dancing in such a way is impressive

'Dancing in such a way is impressive.' 


\section{Analysis: S-HCCs with wie}

The systematic derivation of the meaning of S-HCCs is based on the following core idea: while the basic ingredients - namely equivalence introduced via wie and modalization introduced via an explicit antecedent-are considered fully analogous to those of V-HCCs, S-HCCs involve, both internally and externally, different compositional anchors. These anchors are responsible for the observation made in Sect. 3 that SHCCs do not compare event-internal properties, but rather the broader situations events are parts of.

Let us first sketch a plausible internal structure for S-HCCs such as (104a) (see (32) above). I propose (104b).

(104) a. Bella schweigt, wie wenn sie beleidigt ist.

Bella keeps silent how if she offended is

'Bella is keeping silent, as when she is offended.'

b. (Bella schweigt,) $\left[C P \mathrm{wie}_{i}\left[\mathrm{OP}_{\forall} \ldots\left[{ }_{A s p P} \mathrm{t}_{i}\left[{ }_{A s p P} \ldots \mathrm{V}\right.\right.\right.\right.$ wenn sie beleidigt ist]]]].

The crucial aspect of (104b) is that wie is not moved from a position that is adjacent to the verbal head of the silent matrix clause, as is the case within V-HCCs; recall (45b) from Sect. 4.1.1. This rules out relating wie to event-internal properties; by contrast, I suggest that wie is moved from a position of the silent consequent that allows access to the topic situation against which the silent consequent as a whole is evaluated (see, amongst others, Maienborn 2003a and Kratzer 2010 for details on topic situations). As far as I see, it is very difficult to argue (on empirical grounds) for one of several possible implementations of this idea; for concreteness, I here assume that wie's trace is left-adjoined to a silent AspP (see Maienborn 2003a: 160f for compositionally linking topic situations to aspect and Frey 2003, 2004 and Bücking 2012 for further discussion).

The composition is now straightforward: the internal silent AspP denotes a set of topic situations, as in (105a); I mark topic situations by *. Analogously to the implicit events within V-HCCs, their content is not explicitly given. (The conditional antecedent is not interpreted here, as it relates to the silent operator $\mathrm{OP}_{\forall}$.) In its base position, wie contributes the familiar equivalence relation, as repeated in (105b). The application of MOD* yields (106), while the subsequent inclusion of the antecedent via the silent operator yields (107).

a. $\llbracket[\operatorname{Asp} P \ldots \mathrm{V}$ wenn sie beleidigt ist $] \rrbracket^{w, f, g}$

$$
=\lambda s^{*} \exists e^{\prime}\left[\llbracket \ldots \mathrm{V} \rrbracket\left(e^{\prime}\right) \wedge e \leq s^{*}\right]
$$

b. $\llbracket t_{i} \rrbracket^{a}=\lambda y \cdot \operatorname{sim}^{\prime}(y, a(i), F)$

(106) $\llbracket\left[A \operatorname{Asp} P \mathrm{t}_{i}[\operatorname{Asp} P \ldots V\right.$ wenn sie beleidigt ist $\left.]\right] \rrbracket^{w, f, g, a}$

$=\left[\mathrm{MOD} *\left(\llbracket t_{i} \rrbracket^{a}\right)\right]\left(\llbracket[\right.$ Asp $P \ldots V$ wenn sie beleidigt ist $\left.] \rrbracket^{w, f, g}\right)$

$=\lambda s^{*} \exists e^{\prime}\left[\llbracket \ldots \mathrm{V} \rrbracket\left(e^{\prime}\right) \wedge e \leq s^{*} \wedge R\left(s^{*}, v\right) \wedge \operatorname{sim}^{\prime}(v, a(i), F)\right]$

(107) $\llbracket\left[\mathrm{OP}_{\forall} \ldots\left[{ }_{\text {Asp } P} \mathrm{t}_{i}[\operatorname{Asp} P \ldots V\right.\right.$ wenn sie beleidigt ist $\left.\left.]\right]\right] \rrbracket^{w, f, g, a}$

$$
\begin{aligned}
=1 & \text { iff } \forall w^{\prime}\left[w ^ { \prime } \in \operatorname { B e s t } _ { g ( w ) } \left(\bigcap \left(f ( w ) \cup \left\{\left\{w^{\prime \prime}: \exists e^{\prime \prime}\left[e^{\prime \prime} \leq w^{\prime \prime}\right.\right.\right.\right.\right.\right. \\
& \left.\left.\left.\left.\wedge \operatorname{offended}^{\prime}\left(e^{\prime \prime}, \text { Bella }\right)\right]\right\}\right\}\right) ; \forall e\left[e \leq w^{\prime} \wedge \operatorname{offended}^{\prime}(e, \text { Bella }) ; \exists s^{*} \exists e^{\prime}\right. \\
& {\left.\left.\left[e \leq s^{*} \wedge e^{\prime} \leq s^{*} \wedge \llbracket \ldots \mathrm{V} \rrbracket\left(e^{\prime}\right) \wedge R\left(s^{*}, v\right) \wedge \operatorname{sim}^{\prime}(v, a(i), F)\right]\right]\right] }
\end{aligned}
$$


Finally, $\lambda$-abstraction as triggered by the moved binding relative pronoun renders the assignment-dependent entity $\lambda$-bound. This gives us (108) for the whole S-HCC. We will abbreviate this interim result to (109). (The capital letters again symbolize that there are (infinitely) many $s_{\text {hypo }}^{*}$ and $v$.)

$$
\begin{aligned}
& \llbracket\left[C P \text { wie }_{i}\left[\mathrm{OP} \forall \ldots\left[\operatorname{AspP} \mathrm{t}_{i}[\operatorname{Asp} P \ldots V \text { wenn sie beleidigt ist }]\right]\right]\right] \rrbracket^{w, f, g, a} \\
& =\lambda x \forall w^{\prime}\left[w ^ { \prime } \in B _ { \text { Best } } ( w ) \left(\bigcap \left(f ( w ) \cup \left\{\left\{w^{\prime \prime}: \exists e^{\prime \prime}\left[e^{\prime \prime} \leq w^{\prime \prime}\right.\right.\right.\right.\right.\right. \\
& \left.\left.\left.\left.\left.\wedge \text { offended }^{\prime}\left(e^{\prime \prime}, \text { Bella }\right)\right]\right\}\right\}\right)\right) ; \forall e\left[e \leq w^{\prime} \wedge \operatorname{offended}^{\prime}(e, \text { Bella }) ; \exists s^{*} \exists e^{\prime}\right. \\
& \left.\left.\quad\left[e \leq s^{*} \wedge e^{\prime} \leq s^{*} \wedge \llbracket \ldots \mathrm{V} \rrbracket\left(e^{\prime}\right) \wedge R\left(s^{*}, v\right) \wedge \operatorname{sim}^{\prime}(v, x, F)\right]\right]\right] \\
& \lambda x \exists S_{\text {hypo }}^{*}\left[R\left(S_{\text {hypo }}^{*}, V\right) \wedge \operatorname{sim}^{\prime}(V, x, F)\right]
\end{aligned}
$$

The next step concerns the link between the S-HCC as a whole and its external matrix host. The clear non-integration of S-HCCs (recall the observations made in Sect. 3) suggests a high adjunction site; so, here we do have empirical reasons for adjunction above the VP-level. In keeping with the proposal for different levels of clausal linkage in Reis (1997), I assume that S-HCCs adjoin at the CP-level; see (110).

(110) $\left[{ }_{C P}\left[{ }_{C P}\right.\right.$ Bella schweigt $],[C P$ wie wenn sie beleidigt ist $\left.]\right]$.

Note as well that CP-adjunction is not confined to the right periphery. Reis and Wöllstein (2010) show that verb-first conditionals in German are syntactically unintegrated, even if fronted. In order to capture their non-integration, Reis and Wöllstein argue for their adjunction to the left of the finite verb, as in (111). This position is feasible for S-HCCs as well, as shown by (112) (see Bücking 2015 for details on the topological behavior of HCCs in general).

(111) $[C P[C P$ Regnet es $],[C P$ bleiben wir zu Hause $]]$.

$\left[{ }_{C P}\left[{ }_{C P}\right.\right.$ rains it $][C P$ stay we at home $\left.]\right]$

'If it rains, we will stay at home.'

(see Reis and Wöllstein 2010: ex. (102a))

(112) $\left[{ }_{C P}[C P\right.$ Wie wenn sie beleidigt ist $],[C P$ schweigt Bella $\left.]\right]$.

One can safely conclude that S-HCCs modify neither the given matrix event nor any of its internal components; these options would need the VP or the verbal head as their compositional anchors. Instead, I assume that CP-adjunction is compatible with relating the S-HCC to the topic situation of the matrix clause, $s^{*}$ in the following; this yields - applying MOD* and existential closure of events and situations as usualthe representation in (113).

$$
\begin{gathered}
\llbracket[C P[C P \text { Bella schweigt }],[C P \text { wie wenn sie beleidigt ist }]] \rrbracket \\
=1 \text { iff } \exists s^{*} \exists e \exists S_{\text {hypo }}^{*}\left[R^{\prime}\left(s^{*}, v^{\prime}\right) \wedge e \leq s^{*} \wedge \text { keep silent }(e)\right. \\
\left.\wedge \operatorname{ag}^{\prime}(e, \text { Bella }) \wedge R\left(S_{\text {hypo }}^{*}, V\right) \wedge \operatorname{sim}^{\prime}\left(V, v^{\prime}, F\right)\right]
\end{gathered}
$$

Logical forms for sentences modified by S-HCCs then say that the equivalence relation brought in by wie holds between topic-related entities-the entities $V$ are made available by the hypothetical topic situations of the silent consequent, while $v^{\prime}$ relates to the topic situation of the explicit matrix clause. 
The given underspecified representation calls for a conceptual enrichment. According to MOD*, $R$ is the identity function if the composition takes place where the conceptual structure of the modifier's target is no longer available. In the verbal domain, this is the case at the phrasal level; recall from the preceding sections that, thus, VP-modifiers relate to events as wholes while head-related modifiers target their internal structure. According to the structure above, both the internal wie and the SHCC adjoin to full XPs; that is, one can conjecture that they target the relevant topic situations as wholes as well. So, using identity for both $R$ and $R^{\prime},(113)$ can be simplified to (114); accordingly, the topic situations themselves are said to be equivalent to each other.

$$
1 \text { iff } \exists s^{*} \exists e \exists S_{\text {hypo }}^{*}\left[e \leq s^{*} \wedge \operatorname{keep~silent}^{\prime}(e) \wedge \operatorname{ag}^{\prime}(e, \text { Bella }) \wedge \operatorname{sim}^{\prime}\left(S_{\text {hypo }}^{*}, s^{*}, F\right)\right]
$$

The crucial question now is how equivalence between situations is defined. Or, in other words, in relation to what kind of attribute spaces $F$ can situations be considered as equivalent? I would like to put forward the hypothesis that situations are characterized by their subsituations, including relevant event descriptions. This is captured by the generalized measure function $\mu_{\text {situation }}$ in (115), which maps situations from the universe of situations onto concepts for subsituations.

$$
\mu_{\text {Situation }}: U_{\text {Situation }} \rightarrow v \in\{\text { CONTAins Sit. A, CONTAINS SIT. B }, \ldots\}
$$

Given this, ' $\operatorname{sim}^{\prime}\left(x, x^{\prime}, F\right)$ ' holds for situations $x$ and $x^{\prime}$ iff both situations receive the same values in this attribute space, that is, iff both situations contain situations of the same type.

In the case of modification by S-HCCs, the external matrix topic situation is characterized by the fact that it contains an event of a particular type. For the example under discussion, this allows us to specify a corresponding value in the attribute space; see (116).

$$
\begin{aligned}
& \mu_{\text {Situation }}: \\
& U_{\text {Situation }} \rightarrow v \in\{\text { CONTAINS-AN-EVENT-OF-B.-KEEPING-SILENT, } \ldots\}
\end{aligned}
$$

The event description within the matrix host is the only explicit information that the comparison of the matrix situation and the hypothetical situations can build upon. Following the definition for similarity from above, ' $\operatorname{sim}^{\prime}\left(S_{\text {hypo }}^{*}, s^{*}, F\right)$ ' then holds if both the topic situation $s^{*}$ and the hypothetical situations $S_{\text {hypo }}^{*}$ are equivalent regarding the given subsituation. (117) fleshes this out by using the corresponding classifying function.

$$
\begin{aligned}
& \text { contains-an-event-of-bella-keeping-silent } \\
& \quad=\text { contains-an-event-of-bella-keeping-silent }\left(\mu_{\text {SITUATION }}\left(\mu_{\text {SITUATION }}^{*}\left(s^{*}\right)\right)\right.
\end{aligned}
$$

Intuitively, the resulting interpretation is correct: by using a sentence such as (104a), a speaker asserts that Bella keeps silent while he/she also conveys that the same kind of event, that is, an event of keeping silent, would exist in situations where she is offended.

The positive ramifications of the proposed analysis of S-HCCs are as follows. First, the semantic distinction between V-HCCs and S-HCCs is traced back to a distinction between structural inputs; apart from this, a fully analogous treatment can be 
maintained. Second, the proposed analogy correctly predicts that S-HCCs are subject to the same range of accessibility relations as V-HCCs are. In particular, the speaker does not commit to the truth of the embedded antecedent; he may just suggest its truth under an epistemic reading. Third, the use of equivalence couched in terms of attribute spaces assures that the topic situations to be compared are not considered as identical, but rather as equivalent regarding the concepts of their subsituations; recall the equivalence-based paraphrases of S-HCCs and the corresponding distinction between wie and pro-forms such as das ('this/that'). Note as well that the analysis does not say that the matrix topic situation and the hypothetical topic situations share identical particular events; they merely share the same type of event, that is, equivalent events. Let me finally comment on a putatively ironic twist of the given analysis the reader might puzzle over. For V-HCCs, I have emphasized that the given matrix event and the hypothetical events are not necessarily equivalent; for the non-eventive S-HCCs, the opposite holds: the matrix topic situation and the hypothetical topic situations are said to share the same type of event, namely the one introduced by the explicit matrix clause. Why is this? For V-HCCs, the equivalence relates to event-internal particularized properties; this is the reason why the eventive hosts themselves may be distinct. For S-HCCs, however, the components relevant for the comparison between topic situations are their subsituations, that is, precisely the events they include. The distinct roles the given event plays in both variants follow straightforwardly from the structural input: in V-HCCs, the event itself outscopes the equivalence requirement imposed on event-internal properties; in S-HCCs, the given event is within the scope of the equivalence constraint imposed on the topic situations.

\section{6 als-HCCs}

As pointed out in the introduction, HCCs can also be introduced by als ('as') instead of wie. The external combinatorics of als-HCCs is the same as for wie-HCCs; therefore, their linking to the explicit matrix clause just follows the derivation fleshed out for V-HCCs and S-HCCs with wie in Sects. 4.2 and 5. This is nice, as the corresponding core aspects of the proposed analysis can be generalized across form types. However, the internal combinatorics of als-HCCs differs significantly from their counterparts with wie. This section overviews the main findings and provides an outlook on their formal account.

The structural properties of als-HCCs have been discussed extensively (see Oppenrieder 1991; Jäger 2010; Demske 2014; Bücking 2015). In contrast to wie-HCCs, als can be combined not only with wenn, but also with verb-first position or $o b$ ('whether'), as shown in (118) (see (1) in the introduction).

(118) a. Ben fährt Rad als $\{$ wenn / ob $\} \quad$ er betrunken wäre.

Ben cycles as $\{$ if / whether $\}$ he drunk were

'Ben is cycling as if he were drunk.'

b. Ben fährt Rad als wäre er betrunken.

Ben cycles as were he drunk 
Both additional options are unexpected from a (fully) regular compositional perspective: verb-first clauses have a conditional interpretation. However, they are usually not integrated in their host clauses (see Sect. 4.1.1), which calls for a syntactic configuration that licenses their exceptional integration. The situation for $o b$ is even worse: it does not introduce conditional antecedents, but indirect polar questions, as shown in (119). So-called irrelevance conditionals such as (120) do not contest this claim since they are both formally and semantically different from standard hypothetical conditionals. $^{23}$

a. * Ob es schneit, fahren wir in die Berge.

whether it snows go we in the mountains

'Whether it snows, we will go on a trip to the mountains.'

(see Bücking 2015: ex. (13a))

b. Ben will wissen, ob es schneit.

Ben wants know whether it snows

'Ben wants to know whether it is snowing.'

(120) Ob es schneit oder nicht, wir fahren in die Berge.

whether it snows or not, we go in the mountains

'Irrespective of whether it snows or not, we will go on a trip to the mountains.'

(see Bücking 2015: ex. (13b))

Moreover, the example in (121) shows that als-HCCs strictly forbid an explicit consequent.

$$
\begin{aligned}
& \text { * Ben fährt Rad, als er Rad fahren würde, wenn er betrunken wäre. } \\
& \text { Ben cycles as he cycle would if he drunk were } \\
& \text { 'Ben is cycling as he would cycle if he were drunk.' }
\end{aligned}
$$

The structural idiosyncrasies go along with semantic idiosyncrasies. As shown by (122), als is generally deviant in equatives, which is at odds with the equative function of als-HCCs.

$$
\begin{aligned}
& \text { * Ben ist so betrunken als Mia. } \\
& \text { Ben is so drunk as Mia } \\
& \text { 'Ben is as drunk as Mia.' }
\end{aligned}
$$

Furthermore, the set of readings available for als-HCCs is limited. With a verb form in the counterfactual subjunctive, they receive a counterfactual reading, as exemplified by (123). With a verb form in the reportative subjunctive or the indicative, they receive an epistemic reading, as exemplified by (124). By contrast, extensional or

\footnotetext{
${ }^{23}$ There do not seem to be hidden correspondences between conditionals and polar questions either. Reis and Wöllstein (2010: 133f) point out that polar questions with $o b$ put up for discussion the choice between a positive and a negative alternative (that is: Does a proposition $p$ hold or not?); Reis and Wöllstein refer to Eckardt (2007) for a more detailed discussion of embedded polar questions. Hypothetical conditional antecedents, by contrast, only invoke the positive alternative (that is: What is the case if a proposition $p$ holds?).
} 
generic readings are impossible, even if wenn and the indicative is used. So, the example (125) has an epistemic reading, whereas it cannot convey that Ben is cycling as he always or usually does when drunk. ${ }^{24}$

a. Ben fährt Rad, \{als \{ob / wenn $\}$ er betrunken wäre / als wäre er Ben cycles $\quad\{$ as $\{$ whether / if $\}$ he dunk were / as were he betrunken\}. drunk\}

b. 'Ben is cycling as he would cycle if he were drunk.'

a. Die Katze verhält sich, \{als ob sie Angst hat / als habe sie Angst $\}$. the cat behaves $\{$ as whether it fear has / as have it fear

b. 'The cat is behaving as, in my view, it must behave if it is scared.'

a. Ben fährt Rad, als wenn er betrunken ist. Ben cycles as if he dunk is

b. 'Ben is cycling as, in my view, he must cycle if he is drunk.'

Notably, the existing literature is preoccupied with the question of whether wie-VHCCs are 'closer to reality' than als-V-HCCs are; compare Hahnemann (1999: 229231) for a critical survey and further references. From the perspective of the present approach in terms of accessibility relations, this impression follows from the fact that only V-HCCs with wie allow extensional readings, which are bound to the actual world.

Two comments are in order. First, Oppenrieder (1991: 263) suggests that fully 'real' HCCs should be treated as separate constructions. The present proposal can dispense with this assumption by giving a fully regular explanation in terms of accessibility relations (namely, by assuming a totally realistic conversational background, as shown in Sect. 4.1). Second, and correctly I believe, the proposal does not predict the distinction between wie and als to be clear-cut: notably, wie allows nonextensional readings as well. In addition, als is not necessarily 'unreal' to begin with. On the epistemic reading, V-HCCs with als (and wie) involve belief-based alternative worlds and are thereby suggestive of the way things are in the relevant actual world; thus, a classification based on accessibility relations seems to be more adequate than one based on \pm real.

In the light of the syntactic and semantic idiosyncrasies of als-HCCs, their analysis in terms of regular free relatives is certainly a non-starter. In fact, the prevailing syntactic analyses of als-HCCs consider als a head above a CP, as sketched in (126) (see Jäger 2010; Demske 2014; Bücking 2015 for different implementations).

$$
[X P \text { als }[C P\{\text { wenn / ob / verb-first position }\} \ldots]]
$$

\footnotetext{
${ }^{24}$ One may ask how the indicative and the reportative subjunctive are distributed in epistemic als-HCCs. Roughly, the reportative subjunctive is obligatory in als-HCCs with a verb-first conditional, whereas it is marked (to perhaps different degrees) in all other form types; see for instance Oppenrieder (1991: 361). I will not attempt to explain this peculiar distribution here. Oppenrieder (1991: 361f) suggests that the subjunctive is obligatory in als-HCCs with verb-first position because the 'hidden' verb-first position is not readily identifiable as a 'marker of counterfactuality.' I doubt that this is on the right track, given that HCCs under an epistemic reading do not bear a counterfactual interpretation.
} 
Specifically, Bücking (2015) argues for treating als as a preposition that comes along with idiosyncratic selectional restrictions. Crucially, this perspective allows to endow als with arbitrarily fine-grained lexical restrictions in order to comply with its idiosyncrasies. As already pointed out by Bücking (2015), the main question then is to what extent these restrictions are syntactic or semantic in nature. I see two ways to go.

According to the first option, the syntactic requirements are taken to be rather light. They tie als to CPs whose head feature is filled either by a complementizer (as in alsHCCs with $o b$ and wenn) or by V-to-C-movement (as in als-HCCs with verb-first position); see Bücking (2015) for an implementation in terms of Sternefeld's (2006) feature-driven syntax. These syntactic requirements are complemented by more finegrained semantic constraints. The form types with wenn and verb-first position are promising in this respect since both are used for regular conditional antecedents. One may conjecture that, semantically, als selects for conditional antecedents, and maps them directly to the meaning of HCCs as derived in the case of wie. In addition, als can be said to include presuppositions to the effect that the conversational backgrounds $g$ and $f$ are confined either to an epistemic modal base combined with a doxastic ordering source or to an empty modal base combined with a totally realistic ordering; this captures the limited set of readings. The crucial advantage of this first option is that the transparent contribution of wenn and verb-first position is systematically factored into the composition of als-HCCs. The crucial disadvantage, however, is that there seems to be no way of using this option for HCCs with $o b$ as well, precisely because $o b$ does not contribute a conditional antecedent.

The second option takes als-HCCs with $o b$ to be the paradigm case. Accordingly, als-HCCs are treated as basically 'constructional.' That is, the combinatorial options with $o b$, wenn, and verb-first position are hard-coded within the syntactic information that is stored for als. Consequently, ob, wenn, and verb-first position do not contribute anything to the meaning of als-HCCs on their own; instead, als can be assumed to simply map a proposition to the meaning of HCCs as derived in the case of wie. The merit of this second option is that it smoothly covers als $o b$-HCCs. However, it is sobering from an explanatory compositional point of view: the internal semantics of als-HCCs is considered intransparent, despite the fact that wenn and verb-first position are transparent markers for conditionals. I would like to leave this hard nut to crack for future work. ${ }^{25}$

\section{Conclusion}

This paper was concerned with the compositional semantics of hypothetical comparison clauses (= HCCs) in German. While adverbal HCCs (= V-HCCs) are projected in an integrated verb-adjacent position, sentential HCCs (= S-HCCs) are nonintegrated dependent clauses. In both cases, a conditional antecedent licenses universal quantification over hypothetical scenarios which facilitate an equivalence-based

\footnotetext{
${ }^{25}$ One might choose the second option for als $o b$-HCCs only. However, this would require the assumption that the meaning of als in als ob-HCCs differs from that in the other types. Note as well that a full-fledged analysis has to also account for the peculiar distribution of subjunctive vs. indicative mood mentioned in fn. 24 .
} 
comparison: with V-HCCs, particularized properties of hypothetical events and the given matrix event are said to be equivalent relative to conceptual attribute spaces; these event-internal properties are manners of events or properties held by (entities related to) event participants. S-HCCs, by contrast, give rise to an equivalence between hypothetical topic situations and the given topic situation.

More specifically, I argued for the following key merits of the proposal: first, it shows that the meaning of HCCs can be compositionally derived in a fairly regular way. This holds, in particular, for HCCs with wie ('how'), which can be treated on a par with ordinary free relative clauses. Accordingly, wie is a transparent marker for equivalence, while the universal quantification over hypothetical scenarios can be transparently linked to the conditional antecedent introduced by wenn ('if'). HCCs with als ('as'), by contrast, involve syntactic and semantic idiosyncrasies that are hard-coded within the lexical information associated with als. Second, the semantic distinction between V-HCCs and S-HCCs is traced back to the distinction between integration and non-integration as established by independent syntactic criteria. This allows a uniform basis for both variants that can dispense with any additional stipulations. Third, as is needed for HCCs, the proposal leaves considerable room for pragmatic specifications: the $\mathrm{V}$-adjacent projection is systematically linked to a variation between predicative and manner readings, the conditional antecedent and its modal anchor come along with conversational backgrounds that are sensitive to the utterance context, and the given conditional antecedent and the explicit matrix information guide a non-rigid specification of the mediating hypothetical event description. At the same time, however, the analysis keeps track of the constraints HCCs are subject to: the universal force of the modal quantifier, the fact that the implicit hypothetical information is accommodated within the restrictor, and the constraints that are imposed by the equivalence relation tied to wie (and als) such as the ban on crossing predicative and manner interpretations. Recall, finally, the requirements that follow from the syntactic differentiation between V-HCCs and S-HCCs.

To conclude, I would like to point out two open questions. For one, the analysis of als-HCCs needs to be worked out in detail. Specifically, an explicit semantic proposal for the meaning contribution by als must be made. The envisaged full-fledged analysis should answer the question of whether the internal semantics of als-HCCs is derivable from their parts or largely intransparent for a regular compositional derivation.

A second desideratum evolves from a third type of HCC not discussed so far, namely independent HCCs, as in (127).

$$
\begin{aligned}
& \text { Als ob ich hier was zu sagen hätte! } \\
& \text { as if I here anything to say had } \\
& \text { 'As if I had anything to say here!' }
\end{aligned}
$$

Against the background of the present analysis, the working hypothesis is that the independence of such HCCs effectuates an equivalence-based comparison at the level of speech acts. With (127), the speaker may react to the addressee's request for commenting about some relevant subject matter; Oppenrieder (1991: 364) notes that independent HCCs quite generally amount to reactive speech acts. More concretely, the speaker's utterance seems to relate to the felicity conditions of the request: a request 
for making a comment presupposes that the situation is such that the speaker has the pertinent authority. By using a counterfactual HCC, the speaker suggests that the given situation does not resemble such a situation; thereby, he declines the appeal for a comment. A detailed composition along these lines must remain for future research.

In sum, the present approach to HCCs shows how fruitful a detailed analysis guided by compositional principles can be even for complex structures that seem to resist a compositional treatment. It renders transparent regularities (and open questions) that otherwise would have gone unnoticed.

Acknowledgements This research benefited from the support by project A1 of the CRC "Construction of Meaning," funded by the Deutsche Forschungsgemeinschaft. I cordially thank Sarah Zobel, Carla Umbach, and Claudia Maienborn for detailed comments on the first draft of this paper. I am also indebted to all three anonymous reviewers and the associate editor, Louise McNally, for having carefully read earlier versions of the paper. It profited very much from their instructive comments! Finally, I would like to thank the audience of the Colloquium of the CRC 911 "The Structure of Representations" at the University of Düsseldorf for their valuable remarks on a talk I gave on the semantics of hypothetical comparisons clauses.

Open Access This article is distributed under the terms of the Creative Commons Attribution 4.0 International License (http://creativecommons.org/licenses/by/4.0/), which permits unrestricted use, distribution, and reproduction in any medium, provided you give appropriate credit to the original author(s) and the source, provide a link to the Creative Commons license, and indicate if changes were made.

\section{References}

Anderson, Curt, and Marcin Morzycki. 2015. Degrees as kinds. Natural Language and Linguistic Theory 33: 791-828.

Bücking, Sebastian. 2012. Kompositional flexibel-Partizipanten und Modifikatoren in der Nominaldomäne. Tübingen: Stauffenburg.

Bücking, Sebastian. 2014. Elaborating on events by means of English by and German indem. In Empirical issues in syntax and semantics, 10, ed. Christopher Piñón, 19-36. Available at http://www. cssp.cnrs.fr/eiss 10/. Accessed 15 March 2017.

Bücking, Sebastian. 2015. Zur Syntax hypothetischer Vergleichssätze im Deutschen. Zeitschrift für germanistische Linguistik 43: 261-305.

Caponigro, Ivano. 2004. The semantic contribution of wh-words and type shifts: Evidence from free relatives crosslinguistically. In Semantics and Linguistic Theory (SALT) 14, ed. Robert B. Young, 38-55. Ithaca: CLC Publications.

Caponigro, Ivano, and Lisa Pearl. 2009. The nominal nature of where, when, and how: Evidence from free relatives. Linguistic Inquiry 40: 155-164.

Cinque, Guglielmo. 2004. Issues in adverbial syntax. Lingua 114: 683-710.

Davidson, Donald. 1967. The logical form of action sentences. In The logic of decision and action, ed. Nicholas Resher, 81-95. Pittsburgh: University of Pittsburgh Press.

Demske, Ulrike. 2014. Verbstellungsvariation in hypothetischen Vergleichssätzen. Linguistische Berichte 238: 101-140.

Dik, Simon C. 1975. The semantic representation of manner adverbials. In Linguistics in the Netherlands 1972-1973, ed. Albert Kraak, 96-121. Assen: Van Gorcum.

Dölling, Johannes. 1997. Semantic form and abductive fixation of parameters. In From underspecification to interpretation. Working papers of the Institute of Logic and Linguistics, eds. Rob van der Sandt, Reinhard Blutner, and Manfred Bierwisch, 113-139. Heidelberg: IBM.

Dölling, Johannes. 2003. Flexibility in adverbal modification: Reinterpretation as contextual enrichment. In Modifying adjuncts, eds. Ewald Lang, Claudia Maienborn, and Cathrine Fabricius-Hansen, 511552. Berlin: de Gruyter.

Eckardt, Regine. 2007. The syntax and pragmatics of embedded yes/no questions. In On information structure, meaning, and form, eds. Kerstin Schwabe and Susanne Winkler, 447-466. Amsterdam: John Benjamins. 
Eggs, Frederike. 2006. Die Grammatik von als und wie. Tübingen: Narr.

Eisenberg, Peter, Jörg Peters, Peter Gallmann, Cathrine Fabricius-Hansen, Damaris Nübling, Irmhild Barz, Thomas A. Fritz, and Reinhard Fiehler. 2005. Duden. Band 4. Die Grammatik. 7. völlig neu erarbeitete und erweiterte Auflage. Mannheim: Dudenverlag.

Ernst, Thomas. 1994. M-command and precedence. Linguistic Inquiry 25: 327-335.

Ernst, Thomas. 2002. The syntax of adjuncts. Cambridge: Cambridge University Press.

Fabricius-Hansen, Cathrine. 2007. Subjunktor. In Deutsche Wortarten, ed. Ludger Hoffmann, 759-790. Berlin: de Gruyter.

Frey, Werner. 2003. Syntactic conditions on adjunct classes. In Modifying adjuncts, eds. Ewald Lang, Claudia Maienborn, and Cathrine Fabricius-Hansen, 163-209. Berlin: de Gruyter.

Frey, Werner. 2004. A medial topic position for German. Linguistische Berichte 198: 153-190.

Frey, Werner, and Karin Pittner. 1998. Zur Positionierung von Adverbialen im deutschen Mittelfeld. Linguistische Berichte 176: 489-534.

Gehrke, Berit, and Elena Castroviejo. 2015. Manner and degree: An introduction. Natural Language and Linguistic Theory 33: 745-790.

Hacquard, Valentine. 2011. Modality. In Semantics: An international handbook of natural language meaning. Vol. 2, eds. Klaus von Heusinger, Claudia Maienborn, and Paul Portner, 1484-1515. Berlin: de Gruyter.

Hahnemann, Suzan. 1999. Vergleiche im Vergleich. Zur Syntax und Semantik ausgewählter Vergleichsstrukturen mit 'als' und 'wie' im Deutschen. Tübingen: Niemeyer.

Haider, Hubert. 2002. Adverbials at the syntax-semantics interface. In How we say WHEN it happens, eds. Hans Kamp and Uwe Reyle, 53-70. Tübingen: Niemeyer.

Haider, Hubert. 2004. Pre- and postverbal adverbials in OV and VO. Lingua 114: 779-807.

Heim, Irene, and Angelika Kratzer. 1998. Semantics in generative grammar. Malden: Blackwell.

Hinterwimmer, Stefan. 2013. Free relatives as kind-denoting terms. In Genericity, eds. Alda Mari, Claire Beyssade, and Fabio del Prete, 140-156. Oxford: Oxford University Press.

Hobbs, Jerry J., Mark Stickel, Douglas Appelt, and Paul Martin. 1993. Interpretation as abduction. Artificial Intelligence 63: 69-142.

Jäger, Agnes. 2010. Der Komparativzyklus und die Position der Vergleichspartikeln. Linguistische Berichte 224: 467-493.

Kasper, Walter. 1987. Semantik des Konjunktivs II in Deklarativsätzen des Deutschen. Tübingen: Niemeyer.

Kaufmann, Gerhard. 1973. Zu den durch 'als', 'als ob', ‘wie wenn', 'als wenn' eingeleiteten 'Komparativsätzen'. Zielsprache Deutsch 4: 91-111.

Kratzer, Angelika. 1989. An investigation of the lumps of thought. Linguistics and Philosophy 12: 607653.

Kratzer, Angelika. 1991a. Conditionals. In Semantik/Semantics. Ein internationales Handbuch der zeitgenössischen Forschung, eds. Arnim von Stechow and Dieter Wunderlich, 651-656. Berlin: de Gruyter.

Kratzer, Angelika. 1991b. Modality. In Semantik/Semantics. Ein internationales Handbuch der zeitgenössischen Forschung, eds. Arnim von Stechow and Dieter Wunderlich, 639-650. Berlin: de Gruyter.

Kratzer, Angelika. 2010. Situations in natural language semantics. In The Stanford Encyclopedia of Philosophy, ed. Edward N. Zalta. Stanford: CSLI Publications, Edition Fall 2010.

Krifka, Manfred, Francis Jeffry Pelletier, Gregory N. Carlson, Alice ter Meulen, Gennaro Chierchia, and Godehard Link. 1995. Genericity: An introduction. In The generic book, eds. Gregory N. Carlson and Francis Jeffry Pelletier, 1-124. Chicago: University of Chicago Press.

Lewis, David. 1973. Counterfactuals. Cambridge: Harvard University Press.

Maienborn, Claudia. 2001. On the position and interpretation of locative modifiers. Natural Language Semantics 9: 191-240.

Maienborn, Claudia. 2003a. Die logische Form von Kopula-Sätzen. Berlin: Akademie-Verlag.

Maienborn, Claudia. 2003b. Event-internal modifiers: Semantic underspecification and conceptual interpretation. In Modifying adjuncts, eds. Ewald Lang, Claudia Maienborn, and Cathrine FabriciusHansen, 475-509. Berlin: de Gruyter.

Maienborn, Claudia, Helga Gese, and Britta Stolterfoht. 2016. Adverbial modifiers in adjectival passives. Journal of Semantics 33: 299-358.

Menéndez-Benito, Paula. 2013. On dispositional sentences. In Genericity, eds. Alda Mari, Claire Beyssade, and Fabio del Prete, 276-292. Oxford: Oxford University Press. 
Moltmann, Friederike. 2015. States versus tropes. Comments on Curt Anderson and Marcin Morzycki: 'Degrees as kinds'. Natural Language and Linguistic Theory 33: 829-841.

Oppenrieder, Wilhelm. 1991. Irreale Vergleichssätze. In Betriebslinguistik und Linguistikbetrieb. Akten des 24. Linguistischen Kolloquiums, Universität Bremen, 4.-6. September 1989, eds. Eberhard Klein, Françoise Pouradier Duteil, and Karl Heinz Wagner, 357-366. Tübingen: Niemeyer.

Pasch, Renate, Ursula Brauße, Eva Breindl, and Ulrich H. Waßner. 2003. Handbuch der deutschen Konnektoren. Berlin: de Gruyter.

Pauly, Dennis. 2013. Grenzfälle der Subordination: Merkmale, Empirie und Theorie abhängiger Nebensätze. Potsdam: Publikationsserver der Universität Potsdam. Available at http://opus.kobv.de/ubp/ volltexte/2014/7027/. Accessed 15 March 2017.

Pesetsky, David. 1995. Zero syntax. Experiencers and cascades. Cambridge: MIT Press.

Piñón, Christopher. 2008. From properties to manners: A historical line of thought about manner adverbs. In Papers of the Linguistic Society of Belgium. Vol. 3, eds. Lobke Aelbrecht, Dany Jaspers, Frank Brisard, Philippe De Brabanter, Patrick Dendale, and Bert Le Bruyn.

Portner, Paul. 2009. Modality. Oxford: Oxford University Press.

Reich, Ingo, and Marga Reis. 2013. Koordination und Subordination. In Handbuch der Satztypen, eds. Jörg Meibauer, Markus Steinbach, and Hans Altmann, 535-568. Berlin: de Gruyter.

Reis, Marga. 1997. Zum syntaktischen Status unselbständiger Verbzweit-Sätze. In Syntax im Fokus. Festschrift für Heinz Vater, eds. Christa Dürscheid, Karl-Heinz Ramers, and Monika Schwarz, 121144. Tübingen: Niemeyer.

Reis, Marga, and Angelika Wöllstein. 2010. Zur Grammatik (vor allem) konditionaler Verb-erst-Gefüge im Deutschen. Zeitschrift für Sprachwissenschaft 29: 111-180.

Rosengren, Inger. 2003. Clause-final left-adjunction. In Modifying adjuncts, eds. Ewald Lang, Claudia Maienborn, and Cathrine Fabricius-Hansen, 335-362. Berlin: de Gruyter.

Schäfer, Martin. 2013. Positions and interpretations. German adverbial adjectives at the syntax-semantics interface. Berlin: de Gruyter.

Stalnaker, Robert. 1968. A theory of conditionals. In Studies in logical theory, ed. Nicholas Rescher, 98 112. Oxford: Blackwell.

Sternefeld, Wolfgang. 2006. Syntax. Eine morphologisch motivierte generative Beschreibung des Deutschen. Tübingen: Stauffenburg.

Umbach, Carla, and Helmar Gust. 2014. Similarity demonstratives. Lingua 149: 74-93.

von Fintel, Kai. 2011. Conditionals. In Semantics: An international handbook of natural language meaning. Vol. 2, eds. Klaus von Heusinger, Claudia Maienborn, and Paul Portner, 1515-1538. Berlin: de Gruyter. 